\title{
Understanding medicalisation of female genital mutilation/cutting (FGM/C): A qualitative study of parents and health workers in
}

\section{Nigeria}

Otibho Obianwu

Population Council

Adetayo Adetunji

Population Council

Osasuyi Dirisu

Population Council

Follow this and additional works at: https://knowledgecommons.popcouncil.org/departments_sbsr-rh

Part of the Demography, Population, and Ecology Commons, Family, Life Course, and Society

Commons, Gender and Sexuality Commons, and the International Public Health Commons

How does access to this work benefit you? Let us know!

\section{Recommended Citation}

Obianwu, Otibho, Adetayo Adetunji, and Osasuyi Dirisu. 2018. "Understanding medicalisation of female genital mutilation/cutting (FGM/C): A qualitative study of parents and health workers in Nigeria," Evidence to End FGM/C: Research to Help Girls and Women Thrive. New York: Population Council. 


\section{Evidence to End FGM/C}

Research to Help Girls and Women Thrive

\section{UNDERSTANDING MEDICALISATION OF FGM/C: A QUALITATIVE STUDY OF PARENTS AND HEALTH WORKERS IN NIGERIA}

January 2018 


\title{
UNDERSTANDING MEDICALISATION OF FGM/C: A QUALITATIVE STUDY OF PARENTS AND HEALTH WORKERS IN NIGERIA
}

\author{
OTIBHO OBIANWU \\ ADETAYO ADETUNJI \\ OSASUYI DIRISU
}

POPULATION COUNCIL 
The Evidence to End FGM/C: Research to Help Girls and Women Thrive generates evidence to inform and influence investments, policies, and programmes for ending female genital mutilation/cutting in different contexts. Evidence to End FGM/C is led by the Population Council, Nairobi in partnership with the Africa Coordinating Centre for the Abandonment of Female Genital Mutilation/Cutting (ACCAF), Kenya; the Global Research and Advocacy Group (GRAG), Senegal; Population Council, Nigeria; Population Council, Egypt; Population Council, Ethiopia; MannionDaniels, Ltd. (MD); Population Reference Bureau (PRB); University of California, San Diego (Dr. Gerry Mackie); and University of Washington, Seattle (Prof. Bettina Shell-Duncan).

POPULATION COUNCIL

Ideas. Evidence. Impact.
The Population Council confronts critical health and development issues-from stopping the spread of HIV to improving reproductive health and ensuring that young people lead full and productive lives. Through biomedical, social science, and public health research in 50 countries, we work with our partners to deliver solutions that lead to more effective policies, programmes, and technologies that improve lives around the world. Established in 1952 and headquartered in New York, the Council is a nongovernmental, nonprofit organisation governed by an international board of trustees. www. popcouncil.org

Suggested Citation: Obianwu, O., Adetunji A., Dirisu O., January 2018. "Understanding medicalisation of Female Genital Mutilation/Cutting (FGM/C): a qualitative study of parents and health workers in Nigeria." Evidence to End FGM/C: Research to Help Women Thrive. New York: Population Council.

This is a working paper and represents research in progress. This paper represents the opinions of the authors and is the product of professional research. This paper has not been peer reviewed, and this version may be updated with additional analyses in subsequent publications. Contact: oobianwu@popcouncil.org

Please address any inquiries about the Evidence to End FGM/C programme consortium to:

Dr Jacinta Muteshi, Project Director, imuteshi@popcouncil.org

Funded by:

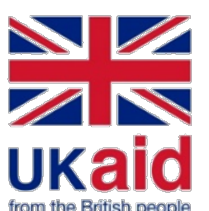

This document is an output from a programme funded by the UK Aid from the UK government for the benefit of developing countries. However, the views expressed and information contained in it are not necessarily those of, or endorsed by the UK government, which can accept no responsibility for such views or information or for any reliance placed on them. 


\section{Table of Contents}

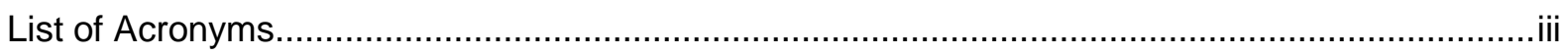

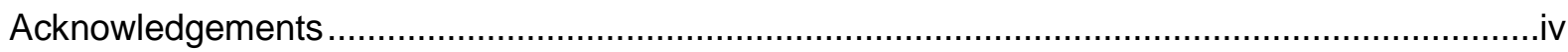

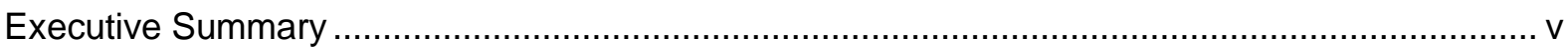

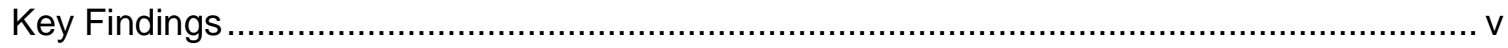

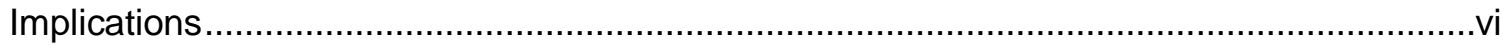

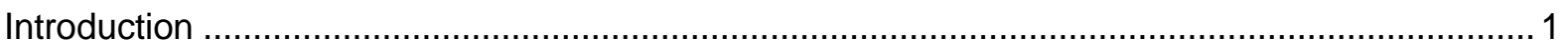

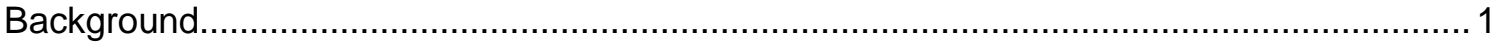

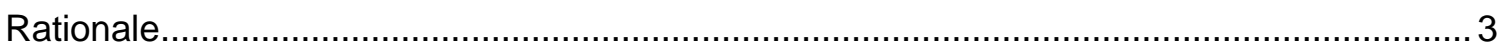

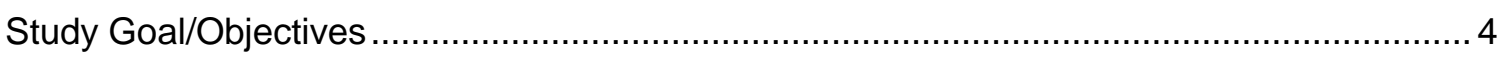

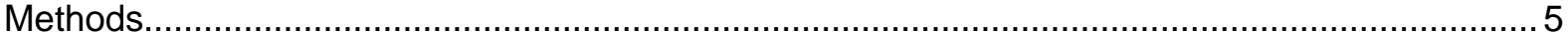

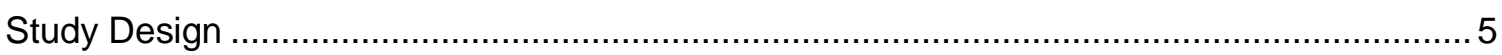

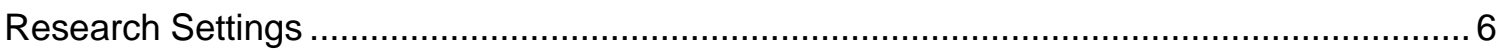

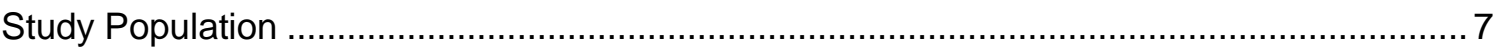

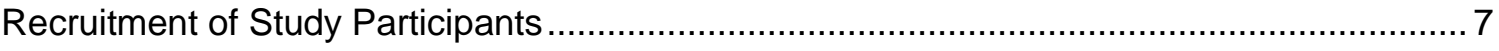

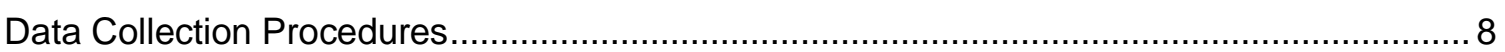

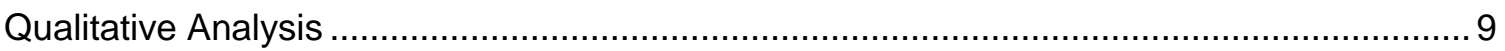

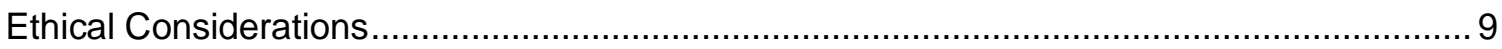

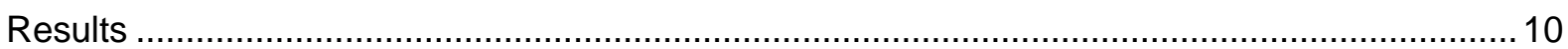

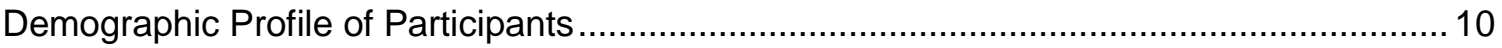

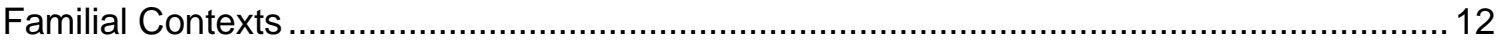

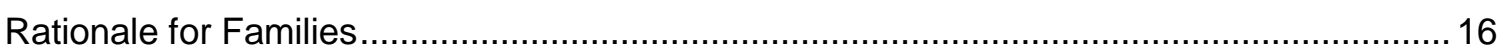

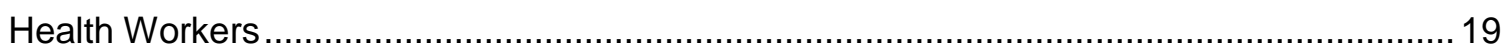

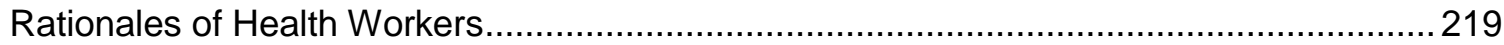

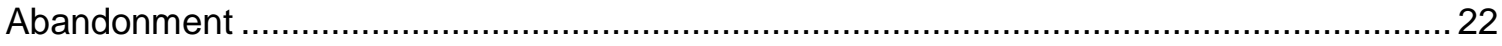

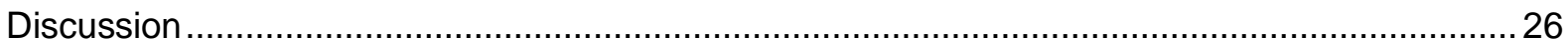

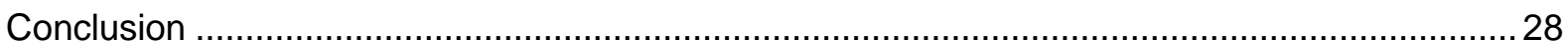

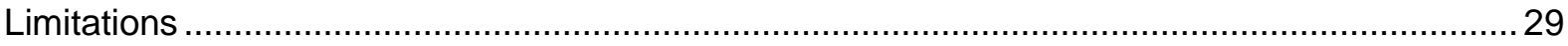

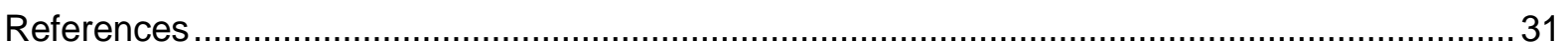

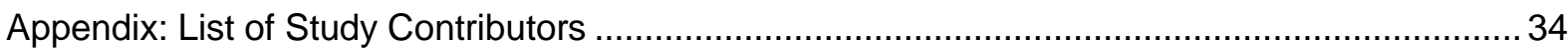




\section{List of Acronyms}

DHS

FCT

$\mathrm{FGM} / \mathrm{C}$

LGA

MICS

NDHS

NPC

TBA

UNICEF

UN Joint Programme

WHO
Demographic and Health Surveys

Federal Capital Territory

Female Genital Mutilation/Cutting

Local Government Area

Multiple Indicator Cluster Survey

Nigeria Demographic and Health Survey

National Population Commission

Traditional Birth Attendant

United Nations Children's Fund

UNFPA-UNICEF Joint Programme on FGM/C

World Health Organisation 


\section{Acknowledgements}

This publication is based on research supported by UK Aid and the UK Government through the Department for International Development (DFID)-funded project "Evidence to End FGM/C: Research to Help Girls and Women Thrive", coordinated by the Population Council. Our team of researchers and contributors were vital to the success of the research process. We thank Professor Bettina Shell-Duncan of the University of Washington, USA, Professor Hazel Barrett of Coventry University, United Kingdom, Dr Christina Pallitto of the World Health Organisation (WHO), Professor Blessing Mberu of African Population and Health Research Centre (APHRC), Nairobi and Professor of Demography and Population Studies University of Witwatersrand, Johannesburg and Dr Babatunde Ahonsi of the United Nations Population Fund (UNFPA), for reviewing the report and offering critical guidance. We especially wish to thank Sylvia Adebajo and Salisu Ishaku of Population Council, Nigeria for their continued guidance and detailed suggestions throughout this effort. 


\section{Executive Summary}

Female genital mutilation/cutting (FGM/C) comprises all procedures that involve partial or complete removal of the external female genitalia, or other injury to the female genital organs for non-medical reasons (WHO 2016). FGM/C is classified into four types (I, II, III, IV) that vary by the anatomical extent of cutting and amount of genital tissue removed. FGM/C has no health benefits but, instead, leads to a myriad of life-threatening and life-worsening complications. The practice is recognised internationally as a violation of the rights of women and girls and reflects ingrained gender inequality. It is estimated that more than 200 million girls and women alive today have undergone FGM/C in 30 countries in Africa, Asia, and the Middle East, where FGM/C is mostly found (UNICEF 2016). Two-thirds of all girls who have undergone FGM/C are from four countries: Egypt, Ethiopia, Nigeria, and Sudan (Shell-Duncan, Naik, Feldman-Jacobs 2015). FGM/C is widespread in Nigeria. According to the 2013 Nigeria Demographic and Health Survey (NDHS), overall FGM/C prevalence in Nigeria is 25 percent among women ages 15 to 49 years old (NPC and ICF 2014). Over half (62\%) of cut women reported FGM/C types I or II.

Despite the local and international call to abandon the practice, there is evidence that some Nigerian families, instead of abandoning the practice outright, are opting for medicalised forms. Medicalisation of FGM/C involves the use of health care providers-doctors, nurses/midwives, or other health professionals - to perform the practice either at facilities or at home; it also includes the procedure of reinfibulation at any point in a woman's life (WHO 2010). Although medicalisation is presumed to reduce the risk of complications, it does not eliminate them and does not alter the fact that $F G M / C$ is a violation of women's and girls' rights to life, health, and bodily integrity. Medicalisation accounts for 12.7 percent of FGM/C practice in Nigeria (NPC and ICF 2014). There is minimal information on medicalisation in Nigeria beyond the prevalence rates available in the Demographic and Health Surveys (DHS) and the Multiple Indicator Cluster Surveys (MICS). Additionally, there is limited understanding of how medicalisation has evolved or is evolving in Nigeria especially as it relates to the prospect of abandonment. The context of decision-making and rationale around medicalisation for families and health workers and the effect of medicalisation on the severity of cutting is also poorly understood.

This community-based, cross-sectional qualitative study, which was conducted in four communities in Nigeria's Delta, Ekiti, Imo, and Kaduna states, was conceptualized to address these gaps in our understanding of medicalisation and to provide critical evidence needed to effectively design abandonment interventions. These states were selected because of their relatively high prevalence of $\mathrm{FGM} / \mathrm{C}$ and medicalisation of $\mathrm{FGM} / \mathrm{C}$, according to data from the Nigeria DHS 2013 (NPC and ICF 2014). These states are also located in the four geopolitical zones (South West—Ekiti; South East—Imo; South South—Delta; North West—Kaduna) of Nigeria, with the highest prevalence of FGM/C practice. In-depth interviews (IDIs) were conducted with parents of girls who had undergone FGM/C by traditional cutters and health workers and health workers who perform, or have performed, FGM/C.

The study findings reveal that the social norms driving FGM/C practice remain entrenched despite a shift to medicalisation. They also reflect the tendency of parents and health workers to view FGM/C, whether traditional or medicalised, as a minor procedure with few complications and significant benefits that would positively impact a daughter's future status as a wife and mother. Minimal public discussion of FGM/C, early age at cutting, the type of FGM/C practiced (Type I, clitoridectomy), limited knowledge of the extent of the procedure and its complications likely contribute to this perception of FGM/C as a benign and valuable practice. With respect to decisionmaking, parents made FGM/C decisions, with the male household head having the final say despite being removed from the mechanics and healing process. In some instances men deferred 
to their wives' opinions as they were deemed most knowledgeable about girls' and women's issues, and in some study communities grandmothers were highly influential in parents' decisionmaking.

Contrary to widely held views that medicalisation occurs because parents are knowledgeable about the health risks of $\mathrm{FGM} / \mathrm{C}$ and are attempting to mitigate them through the use of health professionals, we found that parents reported being unaware of FGM/C's possible physical and psychological complications but chose to use health workers because they perceived them as more careful, knowledgeable, skilled, and hygienic when dealing with any health related matter. Health workers were also viewed as providing more options in cases of emergency and complications. Due to the early age at cutting, typically during infancy, the choice of FGM/C provider was often tied to the type of birth attendant (health worker or traditional birth attendant) who delivered the child. The dynamics of convenience, trust, and cost saving drove the choice of birth attendants. For some parents, FGM/C was offered to them as part of routine neonatal care services. The transition to medicalisation in these communities may be an unintended consequence of improved health seeking behaviours and safe birthing messages.

Although health workers were more knowledgeable than parents about the risks of FGM/C, they performed FGM/C mostly because they shared the same beliefs as community members, on its supposed benefits and perceived approval (or lack of disapproval) by their professional peers. Their practice of FGM/C was not hidden from fellow health workers, and they all learned the practice informally from colleagues. Most participants opined that FGM/C abandonment was plausible in their communities if community members were adequately educated, appropriate community key influencers were engaged, and alternative strategies for enabling sexual restraint were provided. Several participants had already demonstrated their desire to abandon the practice by not cutting their youngest daughters. All but one of the health workers interviewed reported having abandoned the practice.

Our study findings reveal that there is a need for aggressive, consistent, and specific FGM/C abandonment interventions targeting families and key influencers including health workers, traditional cutters, traditional birth attendants (TBAs), and community leaders in the study communities. Such interventions should explicitly discourage medicalisation along with other forms of FGM/C practice and must involve men who are often removed from the mechanics of FGM/C but are key decision-makers. FGM/C elimination strategies have to consider the entire spectrum of risk involved in the practice and address issues of gender equality including women's sexual rights and bodily integrity. Abandonment messages need to target mothers, fathers, and grandmothers, who serve as the key decision-makers for whether girls are cut or not. Actively engaging health workers in advocacy efforts is also necessary, as they can support community sensitisation efforts and de-legitimise the practice for their peers and patients. Interventions focused on health workers must view them not only within their professional capacities but also as community members functioning within FGM/C friendly socio-cultural milieus who may share community social norms. 


\section{Introduction}

\section{Background}

According to the World Health Organisation (WHO), female genital mutilation/cutting (FGM/C) comprises all procedures that involve partial or complete removal of the external female genitalia or other injury to the female genital organs for non-medical reasons (WHO 2016). The procedure has no health benefits and can lead to severe bleeding, problems with urinating and menstruating, cysts, infections, and painful intercourse (Almroth et al 2005, Berg et al 2014, Dare et al 2004, Elnashar and Abdelhady 2007, Knight et al 1999, Njue and Askew 2004). It also causes complications in childbirth and increased risk of newborn deaths (Berg et al 2004, WHO 2006). Psychological effects like anxiety, depression, post-traumatic stress disorder, and low self-esteem have been documented by researchers (Whitehorn 2002, Behrendt and Moritz 2005). FGM/C is recognised internationally as a violation of women's and girls' rights, reflecting ingrained gender inequality (UN General Assembly 2012). It is estimated that more than 200 million girls and women alive today have undergone FGM/C in 30 countries in Africa, Asia, and the Middle East, where FGM/C is concentrated (UNICEF 2016). Each year 3.6 million girls are at risk of FGM/C (UNICEF 2016). Two-thirds of all girls who have undergone FGM/C are from Egypt, Ethiopia, Nigeria, and Sudan (Shell-Duncan et al 2015, UNICEF 2016).

FGM/C is widespread in Nigeria. According to the 2013 Nigeria Demographic and Health Survey (NDHS), overall FGM/C prevalence in Nigeria is 25 percent among women 15 to 49 years old (NPC and ICF 2014). An overwhelming majority (82\%) of FGM/C survivors (aged 15 to 49 years old) were cut before their fifth birthdays (NPC and ICF 2014). These figures hide dramatic differences throughout Nigeria's sub-regions (see Figure 1 for description of Nigeria's geographic regions) and ethnic groups, with prevalence among women ages 15 to 49 ranging from as low as 0.1 percent in Katsina state to 76.6 percent in Osun state (NPC and ICF 2014). The practice, among women ages 15 to 49, is most common in the South West (47.5\%) and South East (49\%) regions, reflecting the fact that FGM/C is mostly practiced by the Yoruba (55\%) and Igbo (45\%) ethnic groups, who reside primarily in these regions (NPC and ICF 2014). The prevalence of FGM/C (among women ages 15 to 49) in the remaining four geographic regions are 25.8 percent in the South South, 20.7 percent in the North West, 9.9 percent in the North Central, and 2.9 percent in the North East.

Figure 1: Prevalence of FGM/C in Nigeria among women ages 15 to 49 years old by geopolitical zone

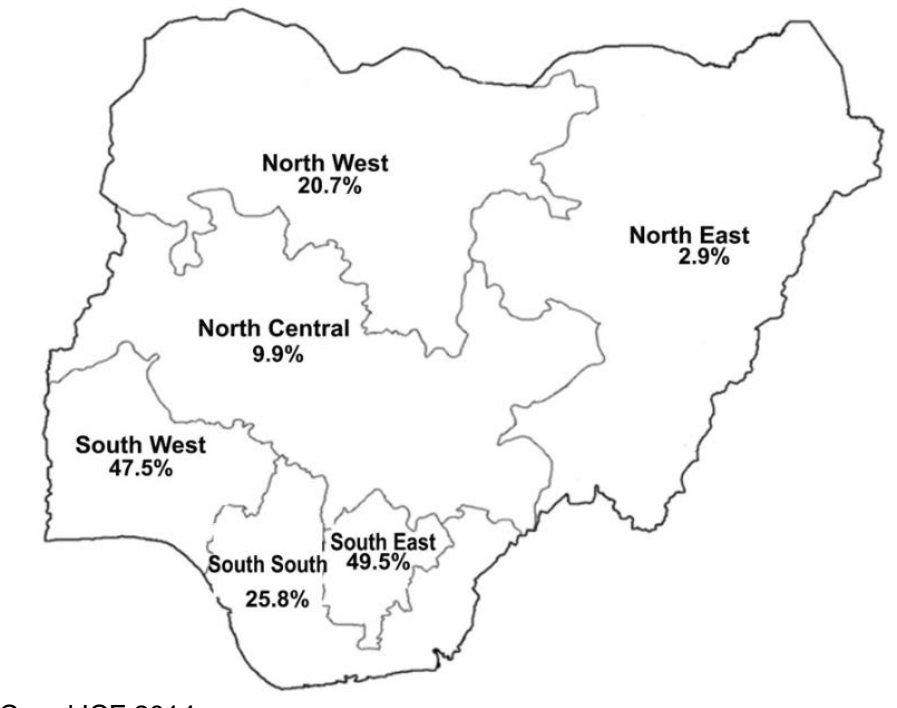

NPC and ICF 2014 
The type of FGM/C performed varies by culture and location. WHO categorises FGM/C into four types:

- Type I-Total or partial removal of the clitoris (clitoridectomy), rarely with removal of the skin around the clitoris (prepuce)

- Type II-Removal of the clitoris and part of the labia minora (excision), with or without excision of the labia majora

- Type III-Narrowing of the vaginal opening by creating a covering seal through cutting and repositioning the labia minora, or labia majora, sometimes through stitching, with or without removal of the clitoris; it is also referred to as infibulation

- Type IV-All other procedures to women's genitalia, for non-medical procedures, such as pricking, piercing, incising, scraping, or introducing substances to the vagina to reduce lubrication; in parts of northern Nigeria, scraping of tissue surrounding the vaginal opening (hymenectomy) is referred to as angurya, while a surgical cut on the anterior or posterior wall is known as gisiri (Mandara 2000, NPC and ICF 2014)

NDHS 2013 found that 'cutting, with flesh removed (which roughly corresponds to type I and II) was reported to be the most common form nationally, with a prevalence of 62.6 percent, while "cut, no flesh removed" (corresponding to nicking, type IV) and "sewn closed" (type III) comprised 5.8 and 5.3 percent, respectively (NPC and ICF 2014). Infibulation (sewing the genital area closed after cutting) was most prevalent in Nasarawa (22\%), Kaduna (21\%), and Bayelsa (20\%) states.

Reasons for engaging in FGM/C are numerous and include tradition and culture, easing childbirth, improving marriage prospects, preventing neonatal death, preventing premarital sex, ensuring marital fidelity, increasing husband's sexual pleasure, stopping clitoral growth, hygienic and aesthetic purposes, and religious approval (Alo and Gbadebo 2011, a et al 2012, Ahanonu and Victor 2014, Ashimi and Amole 2015, Ashimi et al 2015).

As elsewhere, in Nigeria efforts have been, and are being, made to discourage FGM/C. In addition to interventions by health care professional associations, civil society organisations, and the United Nations (UN) system, the government has sought to create an enabling policy environment for abandonment. In 1994, the Nigerian Department of Women's Affairs succeeded in getting the government to issue a decree outlawing the practice. Similarly, since 1999 several states (Bayelsa, Cross River, Edo, Ekiti, Enugu, Imo, Ogun, Osun, and Rivers) have passed laws criminalising FGM/C (Ras-Work 2009, Ezenyeaku et al 2011, Imo state Child Rights Law 2004). The Federal Ministry of Health has also developed a National Policy and Plan of Action for the Elimination of Female Genital Mutilation in Nigeria to guide abandonment interventions from 2013 through 2017 (Federal Ministry of Health 2013).

In 2015, a provision of the Violence Against Persons (Prohibition) Act, federal legislation, criminalised FGM/C, with imprisonment up to four years and a maximum fine of 200,000 Naira (equivalent to $\$ 648$ U.S. dollars) ${ }^{1}$ for persons performing, engaging, attempting to engage, aiding, or counseling a person in circumcision or genital mutilation on girls or women. Because Nigeria has a federal system of government whereby states are autonomous, for certain types of legislation, this new federal law only applies in the Federal Capital Territory (FCT). The law cannot apply nationally until it is approved by 23 of the 36 states in Nigeria, which has not yet occurred. Despite these efforts, current anti-FGM/C laws are poorly enforced (Osuizigbo 2016, Daly and Carson 2016).

In Nigeria, FGM/C is still largely performed by traditional cutters (traditional circumcisers and traditional birth attendants), but there is evidence that families, instead of abandoning the practice,

${ }^{1}$ Based on the exchange rate as of July 31, 2017 
are opting for more medicalised forms (Orubuloye et al 2000, Mandara 2000, Ugboma et al 2004, Onuh et al 2006, Adekanle et al 2011, NPC and ICF 2014, Umar and Oche 2014). WHO defines FGM/C medicalisation as 'situations in which FGM is practiced by any category of health-care provider, whether in a public or a private clinic, at home or elsewhere; It also includes the procedure of re-infibulation at any point in time in a woman's life'. Although medicalisation is presumed to reduce risks of complications, it does not eliminate them, and does not change the fact that FGM/C is a violation of girls' and women's rights to life, health, bodily integrity, and freedom from torture and cruel, inhuman or degrading treatment. Several other frequent assumptions about medicalisation include sharply rising rates of medicalisation, that it does or does not minimise the degree of cutting, and that it does or does not legitimise the practice.

NDHS 2013 reveals that 11.9 percent of girls (ages 0 to 14) and 12.7 percent of women (ages 15 to 49) were "circumcised" by a medical professional. Orubuloye et al (2000) noted rapid medicalisation among the Ekiti Yorubas, as health providers (mostly nurses) were increasingly performing FGM/C. Orubuloye observed that nurses were practicing a less extensive form (nicking) to minimise complications and limit the amount of attention any complications would draw to their practice. A 1997 survey of 250 Nigerian doctors found that although a majority (80\%) believed medicalising FGM/C would encourage the practice and make eradication difficult, a significant percentage (20\%) felt that if the practice could not be eliminated easily it was in the best interest of girls and women that the practice be conducted by adequately trained physicians, to minimise pain and trauma and prevent complications (Mandara 2000).

A study of 250 health workers in southwestern Nigeria found that almost half (48.4\%) had been asked to perform FGM/C (Adekanle et al 2011). Onuh et al (2006) observed that 24.2 percent of 182 nurses in Benin City, Nigeria reported that some FGM/C forms were not harmful, with 2.8 percent supporting the practice because they viewed FGM/C as beneficial. In the same sample, 6.6 percent of respondents routinely practiced $\mathrm{FGM} / \mathrm{C}$, while another 14.3 percent had performed it, although not routinely; 57.7 percent of the latter reported that they would still perform FGM/C in certain circumstances, such as significant pressure from a girl or woman's family, or significant financial benefits. Their reasons for performing FGM/C were cultural (83.3\%), financial gain (50\%), and preventing patients from going to traditional cutters (25\%).

Additionally, it is important to note that medicalisation of FGM/C in Nigeria is occurring within a health system that is weak and plagued by poor coordination, the fragmentation of services, insufficient resources including drugs and supplies, inadequate and decaying infrastructure, inequity in resource distribution and access to care, and very poor quality of care (Adeloye et al 2017, Welcome 2011). The Nigerian health system is also ineffectively regulated which contributes to the existence of phenomena such as non-trained or unlicensed individuals providing health services to an unknowing public and trained health providers violating professional and/or health facility norms by engaging in unethical behaviour like the provision of FGM/C.

\section{Rationale}

Despite a growing acknowledgment of the shift towards medicalisation in Nigeria, there is a dearth of data beyond what is available in the DHS and multiple indicator cluster survey (MICS) datasets, and a few published research articles on medicalisation in Nigeria. There is limited evidence of whether the shift towards medicalisation in Nigerian communities is a signal of weakening of the social norms sustaining the practice within communities, as a prelude to abandonment and subsequent eradication, or if this shift is evidence of reinforcement of support for FGM/C, which could lead to a loss of gains in abandonment. The exact nature of the shift and specifically whether it leads to a lessening of severity of cutting is unclear. Additionally, the context and rationale for families' decisions to seek a medicalised form rather than abandoning the practice, as well as for health workers' decisions to perform FGM/C is also mostly unknown. 
Research exploring the medicalisation of $\mathrm{FGM} / \mathrm{C}$, from the perspectives of both families and health workers, is essential. This study was designed to fill some of the identified gaps in evidence and to generate findings that will enable advocates, programme implementers, and policymakers working towards abandonment to design strategies and interventions to prevent medicalisation and further contribute to FGM/C eradication efforts.

\section{Study Goal and Objectives}

This study's overall aim is to inform the design and implementation of abandonment interventions through enhanced understanding of the factors of medicalised FGM/C in Nigeria:

1. To better understand the context and rationale for families' decisions of whether to seek a medicalised form of FGM/C rather than abandon the practice

2. To better understand the context and rationale for health workers' decisions to perform FGM/C

3. To identify interventions and approaches that may prevent medicalisation and promote abandonment of FGM/C.

\section{Main Research Questions}

The main research questions include:

1. How and why do families choose to have their daughters undergo a medicalised procedure?

2. How and why do health workers perform FGM/C?

3. What do families perceive as benefits of medicalised FGM/C and consequences of FGM/C abandonment?

4. What interventions or strategies do families and health workers perceive as influencing their decisions not to have FGM/C performed on their daughters?

\section{Theoretical Framework for the Study}

FGM/C is a highly sensitive practice that has continued for a number of reasons across countries and cultures (Shell-Duncan, Naik, Feldman-Jacobs 2015). Some researchers believe a myriad of complex and interrelated socio-cultural factors are responsible for its continuation. Families' FGM/C decisions and behaviours are rarely in isolation, but are typically dependent upon familial or societal expectations and can affect social standing. Individuals' personal preferences can be overshadowed by those with greater power and authority, and individuals or families who choose to abandon FGM/C can face high social costs, including exclusion from social support, events, and opportunities (Shell-Duncan et al 2010, 2011).

Social norms theory is a relevant theoretical framework that enables identification of the factors influencing social norm shifts in FGM/C practice, from traditional cutters to medicalisation instead of outright abandonment (Mackie et al 2015). Bicchieri (2006) describes social norms as rules of behaviour with which individuals comply based upon their belief that most people in their "reference group" follow these rules (empirical expectations) and believe they should follow these rules and/or are willing to sanction them for deviation from these rules (normative expectations). A "reference group" comprises people whose expectations matter to a given individual in a particular situation (Mackie et al 2015): family, close friends, a religious group, village, or community-whoever has strong influence. Social norms are held in place by the reciprocal expectations of people in a reference group. Conforming to expectations leads to a behaviour or action that, when consistent and met with social gains and positive sanctions, reinforces expectations and becomes a social norm. This interdependence of expectation, action, and social gains results in social norms being very resistant to change (Mackie et al 2015). 
It is commonly assumed that families are turning to medicalised FGM/C as a compromise between minimising risk of harm and fulfilling persistent and strongly held reference group expectations. Adhering to FGM/C social norms results in desired social gains, with practitioners accepted within the reference group. Health workers who perform FGM/C appear to respond to demand from families for several reasons, such as shared societal FGM/C expectations and attitudes, harm reduction (their expertise will limit complications from traditional cutters) for a procedure seen as necessary by their patients, in addition to financial gain and social status. Health workers can be encouraged to conduct the practice by other practicing health workers. 


\section{Methods}

\section{Study Design}

To understand the context and rationale for FGM/C motivations, experiences, and policy, this qualitative research study utilised in-depth interviews (IDIs).

\section{Research Settings}

Four states were selected because of their relatively high prevalence of FGM/C and medicalisation of FGM/C, according to data from the Nigeria DHS 2013 (NPC and ICF 2014). The survey found overall FGM/C prevalence in Nigeria at 25 percent, and that 12.7 percent of women 15 to 49 years old reported $\mathrm{FGM} / \mathrm{C}$ performed by a health care professional. These states are also located in the four geopolitical zones (South West—Ekiti; South East—Imo; South South—Delta; North WestKaduna) of Nigeria, with the highest prevalence of FGM/C practice.

Figure 2: FGM/C and medicalisation prevalence in women 15 to 49 years old, by study state

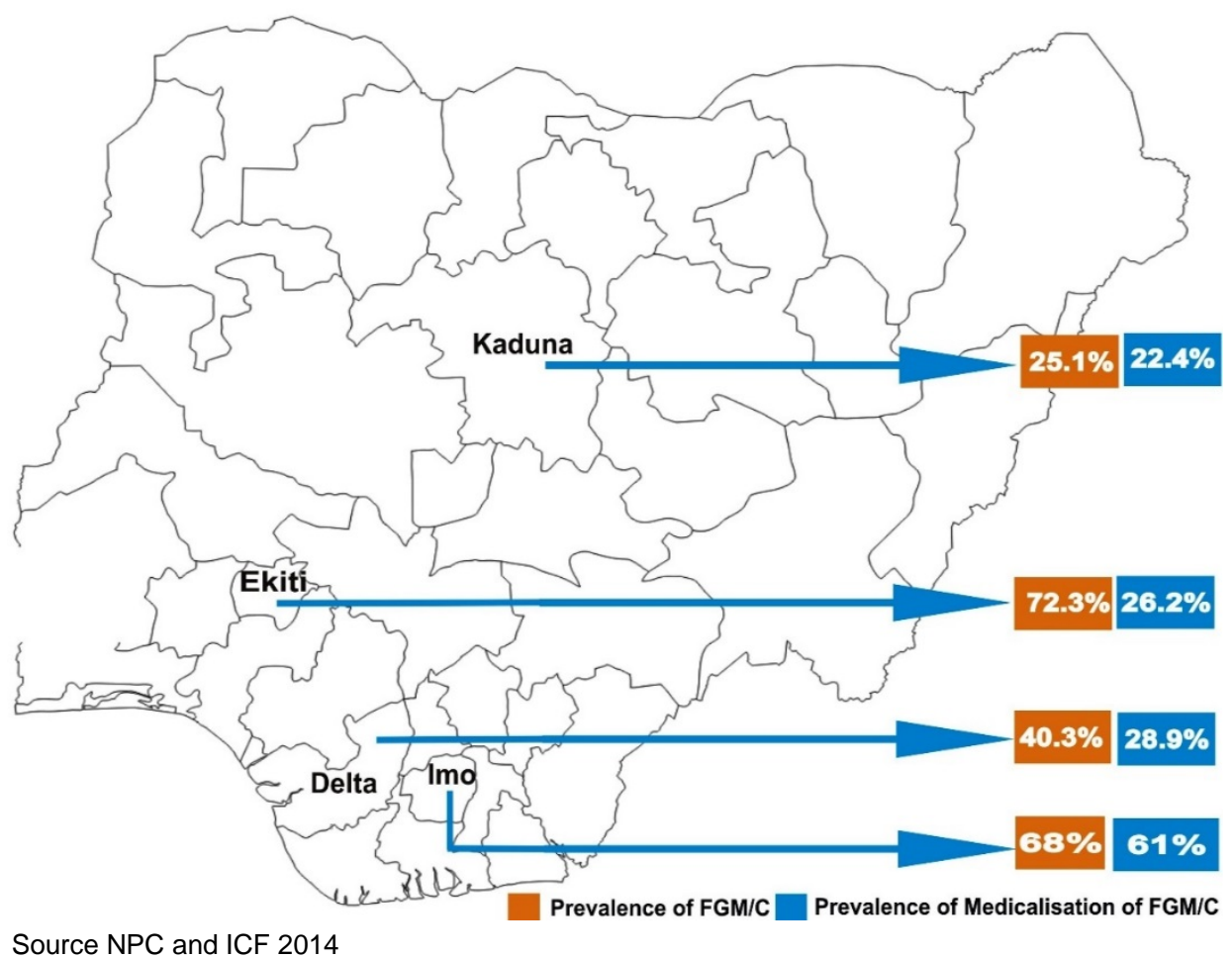

Delta

The study community (Community A) was in Isoko South Local Government Area (LGA). Delta state is part of the South South geopolitical zone, with an estimated population of $4,112,445$ $(2,043,136$ females and 2,069,309 males) within 17,239.24 km² (National Population Commission [NPC] 2009). Delta is an oil producing part of the country, with 25 LGAs. NDHS 2013 found that more than half of men (56.4\%) and less than half of women (42.2\%) had completed secondary school, or had more than a secondary education (NPC and ICF 2014). The state is ethnically diverse, home to the Anioma, Urhobo, Isoko, ljaw, and Itsekiri ethnic groups.

Overall FGM/C prevalence is 40.3 percent among women ages 15 to 49 (NPC and ICF 2014). Mothers report that 9.1 percent of their daughters ages 14 and under have undergone FGM/Cabout half (52\%) of FGM/C is performed at age 15 or older, while 38.7 percent is performed on girls younger than five. A little more than a quarter $(28.7 \%)$ of $F G M / C$ procedures were performed by a health care professional (doctor, nurse/midwife, other health professional). Delta state has a law banning $\mathrm{FGM} / \mathrm{C}$. 


\section{Ekiti}

The study community in Ekiti state (Community B) was located in Ikere LGA. Ekiti is situated in Nigeria's South West geopolitical zone and has an estimated population of 2,398,957 (1,183,470 females and 1,215,487 males) (NPC 2009). Ekiti's land mass covers $5,887.89 \mathrm{~km}^{2}$, and the state has 16 LGAs. The people of Ekiti are culturally homogenous and are a sub-group of the Yoruba. They speak a special dialect of Yoruba language known as Ekiti that varies slightly by community (Ekiti state Bureau of ICT). Agriculture is the primary occupation and major source of income. Twothirds of men (65.9\%) and over half of women (57.6\%) ages 15 to 49 old have a secondary education or greater (NPC and ICF 2014).

Overall FGM/C prevalence is high, with 72.3 percent of women ages 15 to 49 having undergone FGM/C (NPC and ICF 2014). Mothers report that almost half (47.8\%) of their daughters (ages 0 to 14) have undergone FGM/C, which is unsurprising given that the ethnic group with the highest prevalence of $\mathrm{FGM} / \mathrm{C}$ in Nigeria, the Yoruba, are the predominant ethnic group in the state. Yorubas generally offer one specific explanation for the need for FGM/C, to prevent neonatal mortality, as they believe the tip of the clitoris touching an infant's head during birth will result in the infant's death (Orobuloye et al 2000). Most (89\%) FGM/C is performed before the age of five (NPC and ICF 2014).

About one quarter (26\%) of women report FGM/C performed by a health care professional (doctor, nurse/midwife, other health professional) (NPC and ICF 2014). Orubuloye et al (2000), in their 1997-1998 study, noted rapid medicalisation of the practice, as health providers (mostly nurses) were increasingly performing FGM/C. They hypothesised that 'in the modern sector $[\mathrm{FGM} / \mathrm{C}]$ is monopolised by trained nurses, perhaps because doctors are conscious of their training and the attitudes of government health departments'. Nurses who participated in the study noted that they were less influenced by their training against FGM/C than doctors, and many relied on the practice as a source of income. Despite this, nurses' training and the campaign against FGM/C made nurses more cautious and reluctant to draw attention to themselves. Nurses knew the procedure could result in complications, so they were more likely to only nick the clitoris enough to cause visible bleeding, satisfying parents that the procedure had been done, without removing much tissue.

FGM/C is criminalised under Ekiti state's Gender-Based Violence (Prohibition) Law 2011, but enforcement is lax. According to Ekiti anti-FGM/C advocates, the general public is largely unaware of the ban, and most practitioners publicly admit to engaging in the practice without repercussion.

\section{Imo}

The study community in Imo state (Community C) was located in Oguta LGA. Imo state is in the South East geopolitical zone, with an estimated population of 3,927,563 (1,951,092 females and $1,976,471$ males) within $5,182.8 \mathrm{~km}^{2}$ (NPC 2009). The inhabitants of Imo state are Igbos, a culturally homogeneous group. The Igbo language is spoken throughout the state, with slight variations in dialects. According to NDHS 2013, more than half of men (58\%) and women (55\%) had completed secondary school or greater (NPC and ICF 2014).

FGM/C prevalence is high, with 68 percent of women ages 15 to 49 having undergone FGM/C (NPC and ICF 2014), and mothers reporting that 32.3 percent of their daughters (ages 0 to 14) have undergone FGM/C. Almost all reported cases of FGM/C (99.1\%) were performed before age five. Of all states in Nigeria, Imo has the highest prevalence of medicalisation, with 61 percent of women having undergone FGM/C by a health care professional (doctor, nurse/midwife, other). FGM/C is criminalised in Imo state, as a provision of its Child Rights Law 2004. 


\section{Kaduna}

The Kaduna study community was in Kaduna South LGA, while Kaduna state is in the North West geopolitical zone. Kaduna comprises $45,711.19 \mathrm{~km}^{2}$ (NPC 2009) and an estimated population of $6,113,503$ (3,090,438 males and 3,023,065 females). Kaduna is a highly ethnically diverse state with some anecdotal reports estimating that 50 or more ethnic groups are indigenous to the state. Less than half of men (44.9\%) and about a quarter of women (27.1\%) completed secondary school or greater.

Kaduna's FGM/C prevalence is similar to national prevalence, at 25.1 percent for women ages 15 to 49 (NPC and ICF 2014). Mothers reported 27.6 percent of their daughters ages 14 and under having undergone FGM/C. Almost two-thirds (63.2\%) of FGM/C among women ages 15 to 49 was before the age of five, while almost a quarter (22.8\%) occurred at age 15 or later. Infibulation accounted for about 21 percent of FGM/C among women in Kaduna. More than one-fifth of FGM/C (22.4\%) was performed by doctors, nurses/midwives, and other health professionals. Kaduna state does not have any laws prohibiting FGM/C.

\section{Study Population}

The study population consisted of three categories of informants:

1. Parents with daughters or female wards who had undergone FGM/C by a health worker, within the target communities, over the last five years (to enable more accurate recall and current understanding of FGM/C in the selected communities)

2. Parents with daughters or wards who had undergone $\mathrm{FGM} / \mathrm{C}$ by a traditional practitioner in the last five years, to compare attitudes, experiences, perceptions, and decision-making between them and their counterparts who opted for medicalisation

3. Health workers (doctors, nurses, midwives, community health workers) who performed FGM/C; we were also open to interviewing individuals perceived to be health workers by community members.

\section{Recruitment of Study Participants}

As FGM/C is a sensitive issue, we worked through trusted and established community-based organisations and community mobilisers working on women's issues in the study communities to identify and recruit participants. These organisations were mapped prior to the study and were required to be organisations implementing FGM/C abandonment interventions or women-focused interventions (in situations with limited or no FGM/C abandonment interventions). When we were unable to find community-based organisations, we worked directly with community mobilisers or relied upon data collectors to support mobilisation while field work was ongoing. Participants were purposively recruited through referrals from the selected community-based organisations, community mobilisers, and previously interviewed study participants. Community-based organisations recruited participants by identifying a mobiliser from the community through discussions with community gatekeepers like traditional rulers and working with the recommended mobilisers to identify parents and health workers. We planned to recruit four mother-father pairs (2 that medicalised and 2 that used a traditional cutter) and two health workers per study community, for a total of 40 study participants.

One community was selected in each study state (Community A in Delta state, Community B in Ekiti state, Community C in Imo state, Community D in Kaduna state) in collaboration with community organisations (Girls' Power Initiative Asaba in Delta, New Generation Girls and Women Development Initiative [NIGAWD] in Ekiti, Community and Youth Development Initiatives [CYDI] in Imo) and the FGM/C focal person at each state's Ministry of Health. 
Communities were chosen because they were known to the local organisations as communities in which families could be found that utilised health workers for FGM/C, along with families that utilised traditional cutters. Communities were also selected when local organisations believed they could easily mobilise study participants due to prior engagement in that community as they could get vital assistance from community gatekeepers they had worked with previously. Kaduna state had no significant past or present FGM/C interventions, so selection was with a community mobiliser with prior health sensitisation experience in the state.

\section{Data Collection Procedures}

We utilised IDIs as our primary data gathering method because of the sensitive nature of FGM/C in practicing communities. We also planned to gather information that would be quite detailed and personal and believed interviewees would be most comfortable in a direct interview rather than a group discussion. Interviewers with previous experience conducting research, who resided in the selected states, and spoke the local language of sample communities were recruited and centrally trained in Abuja over five days. Each study site had two interviewers, both female in Ekiti and Kaduna, and one female and one male in Delta and Imo. Training topics included qualitative research methods, interviewing skills, transcription, and research ethics. The training workshop also included mock IDIs using the qualitative interview schedule. Interviewers were trained by a qualitative research consultant, together with the principal investigator, and were provided with constructive criticism. Interviewers were also expected to transcribe their mock IDIs.

Field work commenced and was completed over one week in September 2016, with data collection simultaneous in all four study communities. Both research assistants were present for each IDI, with one conducting the interview while the other took notes. IDIs were conducted in the local language. Interviewers utilised a semi-structured interview guide developed in accordance with the study objectives to conduct IDIs in the household or other public space that allowed adequate visual and auditory privacy, such as an empty classroom, government office, or community hall. Within each family, the mother and father were interviewed separately, for comprehensive information, especially on FGM/C decision-making.

Questions in the parental IDI guide aimed at assessing public discussion of FGM/C in their communities, their personal views of FGM/C, reasons for practicing FGM/C, FGM/C decisionmakers, daughters' ages at cutting, types and method of FGM/C chosen and why, cost, awareness of FGM/C complications, steps of a typical FGM/C procedure, and the healing process. The health worker IDI guide assessed how they learned the practice, types of families patronising them, fees, ages of girls and women cut, typical steps of a procedure, type of cut, awareness of complications, reasons they or other health workers provide FGM/C services, and their colleagues' perceptions of health workers who practice FGM/C. Both parents and health workers were questioned about the possibility of their communities abandoning FGM/C, awareness of advocacy interventions for FGM/C abandonment, awareness of criminalisation laws, and the steps they would recommend for ensuring community abandonment of FGM/C.

During field work members of the study team (Population Council and Federal Ministry of Health staff) accompanied research assistants to interviews, to monitor their activities and resolve any issues immediately. Prior to the start of the interviews, informed consent was obtained from each participant. Due to the criminalisation of FGM/C in Ekiti, Delta, and Imo states, only verbal consent was obtained from participants in those states. A waiver of written informed consent was obtained from Population Council's Institutional Review Board to enable rapid anonymisation of participants' personal information to avert risk of arrest or prosecution. In Kaduna, both written and verbal informed consent was obtained. All participants were given a copy of the informed consent form, for their records. All interviews were audio-recorded, with participants' permission. There were no incidences of distress observed during the interviews, except for one instance when a single 
participant refused to answer a specific question. All interviews were completed successfully. Upon conclusion of the interviews, participants were thanked and provided with a transportation reimbursement of NGN 1,500 (equivalent of $\$ 4.70)^{2}$.

\section{Qualitative Analysis}

All audio recordings were directly translated and transcribed, verbatim, into English. Following transcription, all 40 transcripts were reviewed and validated by members of the study team, and other Population Council staff when a language proficiency was required prior to analysis. No personal information, other than assigned participant identification numbers, were included in the transcripts.

Thematic analysis, a versatile adaptive approach for identifying and exploring patterns within data, as well as their links, was utilised. This analytical strategy facilitated description of participants' contexts and experiences with $\mathrm{FGM} / \mathrm{C}$, to answer specific research questions.

The theoretical flexibility afforded by the analytical strategy facilitated its use within the social norms theoretical framework, to understand the links between the social context and FGM/C behaviour. After familiarisation with the transcripts, data were coded by three members of the research team, and the resulting codes were compared to enhance their reliability. The coding process utilised an inductive and deductive approach to identify and extract themes from the data.

\section{Ethical Considerations}

The study protocol was approved by the Population Council Institutional Review Board and the state Ministry of Health's Research Ethics Committee in all four study states. The criminalisation of FGM/C in parts of Nigeria including some of the study sites implied that there was a possibility that anyone admitting to engaging in FGM/C practice risked arrest and prosecution. This meant that in addition to ensuring the expected levels of anonymity and confidentiality required to protect the participants in a study of a sensitive subject matter, we needed to ensure that the personal identifiers of study participants would be rapidly anonymized by removing them from all study materials. This included waiving the requirement for written documentation of informed consent for participants in study sites with a law prohibiting FGM/C.

\section{Results}

\section{Demographic Profiles of Participants}

Interviews were conducted with 34 parents (21 with daughters who had undergone medicalised FGM/C and 13 with daughters who had undergone traditional FGM/C). Six women, who were identified as health workers and had ever performed $\mathrm{FGM} / \mathrm{C}$, were also interviewed. Mobilisers were unable to find health workers who performed FGM/C to interview in Community D in Kaduna state, in addition to any families practicing traditional FGM/C in Community $C$ in Imo state (see Table 1). Although the numbers of health workers interviewed was relatively small, the in-depth nature of the interviews allowed for rich qualitative information to be collected.

\footnotetext{
${ }^{2}$ Based on the exchange rate as of September 2016 when the study was conducted.
} 
Table 1: Number of interviews conducted per study site and respondent type

\begin{tabular}{|l|c|c|c|c|c|}
\hline \multirow{2}{*}{ Respondent Type } & \multicolumn{4}{l|}{ IDls } & $\begin{array}{l}\text { Total } \\
\text { Respondents }\end{array}$ \\
\cline { 2 - 6 } & Delta & Ekiti & Imo & Kaduna & 12 \\
\hline Mother Medicalised FGM/C & 3 & 2 & 4 & 3 & 6 \\
\hline Mother Traditional FGM/C & 2 & 2 & - & 2 & 9 \\
\hline Father Medicalised FGM/C & 2 & 2 & 4 & 1 & 7 \\
\hline Father Traditional FGM/C & 3 & 2 & - & 2 & 6 \\
\hline Health Workers & 2 & 2 & 2 & - & 40 \\
\hline Total Respondents & 12 & 10 & 10 & 8 & \\
\hline
\end{tabular}

Most study participants had some education, ranging from some years of primary school to university or polytechnic degrees. Ekiti had the highest education levels and Kaduna had the lowest. Education was reported by respondents as offered indiscriminately to both boys and girls in their communities. Less than half had jobs as civil servants and health workers, while most respondents were involved in business and trading. Primary economic activities in the four communities were farming and trading; fishing and hunting were also mentioned. Participants' ages were also diverse. The youngest was 24 , while the oldest was about 62 (he did not know his date of birth and had to estimate). Most participants were in their 20s and 30s. All parents were married and had female children, and at some point in the past five years participated in the practice of FGM/C.

Participants were indigenes of the communities where they were interviewed or had lived there long enough to give reliable social norm information. The predominant languages spoken in the communities were Isoko and Pidgin English in Delta, Yoruba in Ekiti, Igbo in Imo, and Hausa in Kaduna; in the Kaduna community a few study participants spoke Yoruba. Christianity was the dominant religion among participants from Ekiti, Delta, and Imo states, while Islam was the predominant religion in Kaduna.

In study Communities $A$ and $B, F G M / C$ was performed by either traditional cutters or health workers. Parents in Community $\mathrm{C}$ in Imo had completely switched to health workers, while in Community $D$ in Kaduna, it was difficult to find parents who had used health workers. In Community $D$, parents who had used a health worker were not indigenous to the community, and some had arranged the procedure in their native communities. Parents who utilised health workers (in Community D) were all Yorubas who resided in the predominantly Hausa community. In Community B in Ekiti there was not a clear separation between traditional cutters and health workers, as the birth attendants (lya Agbebis) mentioned were tied to faith-based maternities (maternities owned by churches, specifically an Apostolic Church in the community) typically staffed by traditional birth attendants (TBAs) as well as retired health workers.

It was unclear if health workers interviewed were true health workers. They were perceived as health workers by community members and identified themselves as such, but upon further questioning some revealed that they were auxiliary nurses or had trained as a nurse at a specific hospital. Only one health worker stated that she was a community health worker (CHW). Half of the health workers were indigenous to the study communities, while the remainder were either from nearby communities or had lived in the study communities for many years. All were women 
and ranged in age from 28 to 59. All except one health worker (the youngest) had children. All health workers with children also had daughters, and all but one had cut her daughter(s). All were from Ekiti, Delta, or Imo states.

\section{Familial Contexts \\ FGM/C as an open secret}

The cutting of girls and women was a cultural practice prevalent in all four study sites. FGM/C was not a topic openly discussed, except possibly among women of the same age group. One parent mentioned health centre discussions about FGM/C abandonment as infrequent opportunities when community members discussed FGM/C openly. Some parents stated that the reason for such silence was due to respect for women's bodies, mistrust of what others would do with such information (this idea was prevalent in Community B in Ekiti), and a fear of supernatural attacks. It appears that FGM/C traditional norms in all communities except Community $C$ in Kaduna were at odds with increasingly visible anti-FGM/C government policies. Some interviewees mentioned that FGM/C was becoming an underground practice, with families and health workers refusing to admit their participation. In all study sites, FGM/C was not tied to any traditional or celebratory ceremony, except in Delta state where it was performed as part of traditional marriage rites. There was consensus that FGM/C is an accepted cultural practice, although not openly discussed.

Is FGM/C something that is talked about or is it covered in silence?

'Nobody will want to go to cut his/her child and will be discussing it openly, nobody. What we just know is that everyone cuts their children. The reasons people don't discuss it openly is because of the spiritual attack and so on'.

Father, Medicalised, Ekiti 2

In your community, do people discuss circumcision openly?

'The discussion only comes up if someone goes to the government owned health center to have her child then she will be told not to circumcise her. Or if you mention that you want to circumcise your daughter, they will tell you not to do it because girls are no longer being circumcised. Some other people will still advice you to go and circumcise her. People talk about it but not too much'.

Mother, Medicalised, Imo 3

\section{Myths and misconceptions about the clitoris}

Both 'health workers' and parents attributed several negative outcomes to uncut women. Across all the study communities, both male and female interviewees expressed the belief that the presence of the clitoris made women have a greater desire for sex, predisposing them to promiscuity and marital infidelity. These kinds of behaviour by women were considered socially unacceptable and in violation of their roles as good mothers and wives. In Community A (Delta), one father mentioned that marital infidelity by women was a cultural taboo with supernatural repercussions. This motivation for FGM/C was interrelated with the perceived need to suppress women's sexual desire as a key strategy for ensuring a woman remained under her husband's control. Narratives around FGM/C were based upon accounts by older people and were not necessarily experiential. Failure to act was viewed as having devastating consequences, as women had no other personal mechanisms for self-control aside from FGM/C.

So, in your opinion, do you think that there is any difference between someone who was circumcised and another who was not?

'Yes, truly there is a difference because I can see it in the young girls today...I was told that an uncircumcised person is always promiscuous but a circumcised girl can control herself and such girls are well behaved'.

Mother, Medicalised, Imo 1

'Before, when we were young, it was said that as long as a woman is not circumcised, she will follow men. Like, if somebody is married...your man will not be enough for you. The person will be looking for men. According to the older generation, I grew up hearing with 
my ears, they will say if somebody grows up and gets married, your husband will not be enough for you. You will start behaving like an Ashawo [prostitute]'.

Mother, Medicalised, Kaduna 1

What is your thought on female circumcision?

'Toh! For me there is something for the girl that has been circumcised, it reduces sexual desires: Even if she grows up she will not be interested in men. She will not have desire for men [sex]: You understand? If it's not cut, then there will be a problem'.

Mother, Medicalised, Kaduna 2

'Before I was born; they have been doing it and I was born into [the culture]. It is a culture. They said every girl must be circumcised'.

Why?

'Just because of sexual urge...they also...said....when [women] are in a man's house, so that they [women] will not have the urge to go out [seek sexual pleasure]'.

Father, Medicalised, Delta 5

'When she is mature she will become wayward, we believe that a girl that is not cut, when she is matured, she will begin to do dirty things around, so that is why we decided to do it on time, to avoid regrets later'.

Father, Medicalised, Ekiti 2

Interviewees also linked the clitoris to poor neonatal and reproductive outcomes. An overwhelming majority of interviewees from Ekiti repeatedly mentioned the belief that if the clitoris touched a newborn's head during childbirth the infant would die, with $\mathrm{FGM} / \mathrm{C}$ being a way to prevent this fate. Adult women's desire for FGM/C was driven by fear and not necessarily experience.

'When I came of age, what my mother told me was that when an uncut woman wants to give birth and the head of her child touches her uncut clitoris, such a child will die. That is what I was told. It was the fear of this that made me cut my daughters'.

That is the only reason?

'That is the only reason I was given. My mother-in-law also told me that it is not good for a woman not to be cut. If such a woman is not cut at infancy, she must eventually be cut in the future at the point of giving birth'.

Mother, Traditional, Ekiti 4

A few interviewees claimed that FGM/C eased childbirth for mothers, with uncut mothers experiencing delivery challenges. Some interviewees also believed an uncut woman could be afflicted with infertility. Concerns over the clitoris predisposing uncut girls to genital itching, and notions on a non-protruding clitoris as a genital beauty ideal were expressed by participants from Imo. FGM/C was thought to prevent these negative outcomes in girls or women who had been cut.

'Female circumcision is good. It is part of the culture of our community, which mandates that when a girl child is born she should be circumcised for the good of her own body. Because any girl who is not circumcised will be disturbed later...They said it causes itching. Like myself, my mother circumcised me, but the part that they are talking about, I do not have an idea. But according to what I heard, they said that it causes itching. If you do not circumcise a girl it will cause her to itch, and she will always put her hand there to scratch it off. And that is how it will keep disturbing her'.

Mother, Medicalised, Imo 2

There was some dissonance observed in parents' beliefs about FGM/C. A father who was uninformed about FGM/C when he had his first daughter and did not cut her, subsequently ensured that his other daughters were cut. Although he held the firm belief that uncircumcised girls became promiscuous, he reported that his first daughter, who was now married, was not promiscuous because she had the ability to comport herself. Another mother from Imo, who was uncut herself yet cut her daughters, felt that she was not affected by promiscuity because of the "Grace of God" and "respecting herself". 


\section{Age at cutting}

In all communities except for Community A (in Delta state), parents reported cutting daughters within the first few months of life. In Community C (Imo), it was overwhelmingly done on the seventh to eighth day of life with only two parents mentioning that the babies were less than one month and six months old, respectively. In Community D (Kaduna), most interviewees reported that a girl was typically cut within days of birth. A similar situation was found in the community in Ekiti state (Community B) with interviewees reporting that their daughters were cut from seven to eight days of birth until about three months.

For Community A (Delta), in the past, daughters were typically cut at the point of marriage or during pregnancy with their first child. This was still reported as a current practice in the community by some participants. Despite this history, most interviewees reported cutting their daughters either as babies or from ages two to seven years old. It appeared that the age at cutting in Community $A$ was declining due to the belief that the pain was less for younger girls than older girls and women.

'Some people, they do it when they get pregnant; most people... when they are pregnant with the first child. Some, because of the pain involved, they do it when the child is still small. It can be any age. As from four you can do it, like the one I did, she was seven'.

Mother, Medicalised, Delta 9

\section{Parental involvement}

Mothers and/or grandmothers were often responsible for taking daughters for cutting and providing post-FGM/C care while fathers contributed to the decision-making on the cutting of daughters and provided funds to pay for the procedure. Most fathers had never witnessed the practice and could only describe the procedure from what they had heard from others. Some fathers were completely unaware of what portion of the external genitalia was being excised while a few believed anything to do with the female body was not in their area of expertise or concern. Some mothers also had not observed the procedure as they were afraid of witnessing their baby's pain.

Do you know what happens during the circumcision operation?

'Actually, like me, anything concerning woman I don't like partaking apart from my wife, even if it's my daughter. So when they did her own, I only employed somebody. They came to my house. I gave the permission and I left the house, so they were in the room doing it, I don't know what happened there'.

Father, Medicalised, Delta 6

\section{Cost}

FGM/C in the four study communities was usually performed at a cost. In some cases, families paid a fee and provided materials for the procedure, or as gifts to the cutter. No particular amount was mentioned as a uniform cost: Charges quoted ranged from 200 NGN (.63 USD) to 5,000 NGN (16 USD) with most below 3,000 NGN (9.4 USD) ${ }^{3}$. One outlier was a family charged 13,000 NGN (41 USD) by a health worker. Some interviewees reported FGM/C as part of the newborn delivery package, part of delivery charges, and they were unable to report the exact charge.

So how much did it cost you to do it?

'Total, everything was eight thousand. That is for the entire delivery of the baby....and including the circumcision'. Mother, Medicalised, Imo 2

The cost of obtaining the procedure is not considered significant, and no interviewee seemed troubled by the cost. Whether the procedure was medicalised or traditionally done did not seem to have a bearing on the cost though the medicalised procedure was slightly more expensive. Some interviewees felt that the traditional cutters were cheaper.

\footnotetext{
${ }^{3}$ Based on the exchange rate as of September 2016 when the study was conducted.
} 


\section{Awareness and experience of FGM/C complications}

In all study communities, a majority of parents had not heard of any serious FGM/C-related complications, and their daughters or wards had never experienced any. When asked about complications, some reported mild to moderate pain, mild fever, and bleeding, which they said resolved quickly. One father mentioned recently learning about the risk of infection, specifically HIV, due to unsterilised instruments. Only one parent, another father in Community A, viewed sexual dysfunction as a complication; he reported sexual relationships outside his marriage, with uncut women, and knew there was a difference between cut and uncut women. He found it difficult to have sex with his wife because there was never mutual sexual interest. For others, this was a benefit of FGM/C, as they believe it curbs promiscuity and reduces female marital infidelity. No parent reported being aware of any negative psychological effect of the practice.

After the circumcision, was there anything? Did she have any problems?

'No, it did not cause any problems. It was just the pains she felt while passing urine which made her cry but it did not bleed so much. She just bled for a day, and the next day the bleeding stopped'.

Have you seen anybody who had complications arising from this procedure?

'I have not seen'.

Mother, Medicalised, Imo 2

What's your own opinion, how do you see female circumcision? Is it a good thing?

'It's not good...When you are romancing someone, that circumcision that they circumcise women, that thing is what bothers women.... when you romance her...Y You know as a man gets aroused is the way a woman also gets aroused. But when they remove that thing [clitoris], the woman will not be getting feeling [will not be aroused]'.

You don't like that thing?

'Yes'.

Father, Traditional, Delta 12

'Recently, I just got to know that it is not o.k.; but to me, the cutting aspect of it, only the cutting aspect of it, and maybe the use of unsterilised knife and all those things, which can lead to... HIV and all those stuff. So that is....and I just heard that recently'.

Father, Traditional, Ekiti 1

\section{Post-FGM/C care and healing process}

Parents reported a period of complete healing from three days up to four weeks. Both traditional and modern methods were used to aid recovery, mostly whether the cut is by a traditional cutter or health worker. Non-medicalised treatments mentioned by interviewees include herbs, engine or crude oil, breast milk, and hot water massage. Some herbs were administered orally, while others were applied topically and used to clean the wound. Conventional medical supplies were also used to aid in healing the wound. Parents and health workers reported using hydrogen peroxide, methylated spirit, antibiotics (penicillin ointment, ampicillin, Ampiclox drops, Flagyl), vitamin C, and iodine. The belief that urine has some healing properties was rampant in all communities. After the child urinated, it was believed the wound was on its way to recovery. No matter the supplies used, cuts did not take long to heal. FGM/C was viewed by families and health workers as a minor operation.

Can you describe to me how the operation was carried out?

'They just cut a small piece of flesh from her vagina. That's all. There was no blood, just the pains. That's all'.

Mother, Medicalised, Kaduna 2

Yes, the place that was cut. How long did it take to heal?

'Let me just say one week...Because I was massaging it with hot water, so as to hasten the healing process. Then, when she is covered and she passes urine, it also helped it to dry up and heal'.

Mother, Medicalised, Imo 2 


\section{Rationale for Families \\ FGM/C decision-making}

Decision-making for whether a girl is cut usually revolved around her parents and grandmother, either paternal or maternal. In some families, the decision was an agreement between husband and wife. The mother did not have FGM/C performed on the child without the father's knowledge, and indeed fathers seemed to hold the power in final decision-making. Although it was often the mother who would take the child for the procedure, the father was fully aware of the decision and gave money for that purpose. In some cases, husbands were the sole decision-makers and wives complied with their wishes while in others, husbands deferred to their wives' decisions as they felt their wives would know better about the need for the practice since they were female.

'I, as the head of the family, told my wife, that since it was the culture we inherited from our fathers and mothers, once we have a baby girl, she should cut her within seven to eight days. Seven to eight days after we gave birth, I told my wife that it was time to go and cut her. We then took her to the hospital to cut her'.

Father, Medicalised, Ekiti 2

Are you the one to make the decision? Is he [the husband] the one who takes the decision? 'Definitely, he is the man; he is the head of the home'.

So he takes the decision?

'Yes'.

So it's not your decision if she will be cut or not?

'No'.

If you don't agree, will they still cut her?

'Surely there are going to be a little ups and down [misunderstanding] in the home, still [it is] the man that should decide what to do'.

Mother, Medicalised, Delta 9

Who cut your daughters? Who took the decision? Are you the one that took the decision or your wife's mother?

'The girls' mother [his wife]

The girl's mother took the decision. Left to you, would you have allowed your children to be cut?

'No, on their own, I'm not part of such things. As my boy is here, I know boys' own is being done. The boy...I'm o.k. with it. Because I don't know that [FGM/C]. As this woman is here, when it's time for delivery, as the woman is pregnant, the man will not be present. It's a woman that knows what happens there. Like women when they enter labour, I cannot say this is the pain that women pass through in labour, you understand. As my woman said its o.k., let us do the thing like this. She knows what it involves...that they said we should do it. You understand'.

You did not support it, but if your wife thinks it's valuable, then you go ahead with it? 'Yes'.

So if women are insisting that it should be done, then it must be done?

'Yes'.

Father, Traditional, Delta 12

Both paternal and maternal grandmothers were very influential in the decision-making in Community A (Delta) and B (Ekiti) and sometimes took the girls for the procedure. There were cases in Community $D$ (Kaduna) where grandmothers played a role but these were among Yoruba study participants and not the Hausa community members who were the dominant ethnic group. In one instance, a maternal grandmother took the girl to be cut against the wishes of the child's 
mother and although the mother was angry there was nothing done about it. Interestingly, two mothers (including a health worker) expressed that they would not influence their children's decisions to practice or not to practice FGM/C.

Was it you who took the decision to cut (circumcise) her or her grandmother, your mother? 'My mother is the one that persuaded us to do it'.

But you took the decision?

'Yes'.

Father, Medicalised, Delta 6

There was dissonance observed in some parents' description of their role in the decision-making process. A mother mentioned that she made the decision for her daughter to be cut but eventually admitted that her husband had the final say. A father in Delta state appeared uncomfortable with the role he played in his daughter's "circumcision" stating that it was his mother-in-law who took the decision to cut his daughter and he only complied with her wish. Upon further probing, he admitted that the procedure would not have occurred without his permission and that he agreed with her recommendation because his mother-in-law would be more informed about FGM/C given her age. He was also willing to allow the procedure to be completed and to observe the outcome.

\section{Who took the decision to have her circumcised?}

'My mother-in-law took the decision. I only took my daughter to meet her...She did it for her daughter [respondent's wife], so she said she would do it for her granddaughter also'. But you agreed... Why did you agree to the process?

'They...the women, know more about it, as regards to their age. They are the elders'. You didn't argue with them at all?

'No, I didn't. I agreed with them to go on with the process. I was of the opinion that if that is the issue; let the process go on and see how it turns out'.

Let's assume you didn't agree to the process: What would have happened?

'They wouldn't have gone on with the process'.

Father, Traditional, Delta 1

\section{Parents' reasons for cutting}

Reasons parents gave for cutting their daughters were largely tied to the ideas that they had about the clitoris and the negative consequences of its non-removal. As described above, parents cut their daughters for the following reasons: to prevent promiscuity and marital infidelity, to ensure marriageability and fertility, to ease child birth, prevent neonatal mortality, to meet cultural standards for the appearance of female genitalia, and to prevent genital itching. Some parents also felt a strong desire to fulfill the culture/tradition that had been passed down from their ancestors or to conform to the social norms around them. Two parents (a mother and a father) in Kaduna, expressed the belief that female "circumcision" was required or viewed positively by Islam.

'It's a cultural practice, we were born to meet it. You understand. Our forefathers introduced all those things. Especially...in my village we still practice it...And in our village we believe that if you don't do it that means you don't belong to the community. Especially when you don't do it people will like..."Ah!"...like when you are old, especially a female, when you are old, there's no husband, no child, people will look for an avenue to look for your trouble, so they can tell you that "Ah! So and look for your husband or go and have your child." That is how it is in our village for a woman who has not done it. People will look for your trouble, saying look at this one that did not...you understand. So they still practice it there, it's our culture'.

Mother, Medicalised, Delta 9

The explanations for choice of FGM/C provider varied among parents. Reasons given by parents who medicalised were that FGM/C with health workers would be less painful, more hygienic, safer, and health workers would be more skilled than a traditional cutter. Medicalised FGM/C was 
considered by families utilising health workers to be safer than using a traditional cutter. Several reasons were advanced for this including that in case of an emergency, there was a lot that health workers and health facilities could do to save the situation. This was unlike the traditional cutters where they believed that there were no measures available to handle an emergency situation. Also, parents did not trust the level of hygiene of traditional cutters' instruments. Additionally, one parent felt that people were choosing medicalisation because they feared that traditional medicine worked for some people but not everyone. Parents were also confident that health workers had better skill and expertise than traditional cutters.

'Nowadays, even when I want to give birth, I don't like all this traditional again. I normally go to the health centre because they are more careful. Carefulness... You know when you have some condition...one condition that is not good those traditional people would not be faster. Faster as in...maybe you are short of blood or your body is doing one kind [having an odd feeling]. They have all those things to place in your body so that you will recover quickly. The highest thing [traditional practitioners] do is buy malt [a soft drink] and milk. That's why I prefer health workers'.

Mother, Medicalised, Delta 2

'The reason why we went there was, if any negative consequences had arisen at the moment of the operation, it would've been promptly taken care of. The child will be well taken care of better than at the traditional cutter's place'.

Father, Medicalised, Ekiti 9

'I gave birth in the hospital where everything is done with good hygiene. We can't compare it with that of a traditional practitioner. I'm not saying that the lya Agbebis [traditional birth attendants] are not clean, but to avoid infections from germs, through what they will use in covering the wound'.

Mother, Medicalised, Ekiti 5

On the other hand, two parents who used traditional cutters felt that the traditional cutters had more skill and were more experienced than the health workers. They believed that a departure from traditional cutters may lead to complications in the circumcision process. It also emerged that some parents chose traditional cutters because they were also the birth attendants that delivered their children. Some reasons parents gave for utilising TBAs were that they were easier to access, more attentive, and cheaper than health workers.

'Some, as a result of poor expertise in the circumcision process, complications may arise. That's the reason some persons prefer the native [local or traditional handlers] to some health workers, and these native people who do female circumcision are old people... mature people who have a good knowledge about the procedure of female circumcision'.

Father, Traditional, Delta 1

'Even in the hospital, a lot of the times you can see that the hospital workers will see a woman [in labour] in pains and not pity her'.

Father, Traditional, Kaduna 4

'No other reason, apart from the fact that I delivered her there. All these lya Agbebis at least will be cheaper than going to the general hospitals...We usually visit where is close to our house, you know, we usually visit the nearest clinic or maternity. That lya Agbebi was very close to our environment, our area, then'.

Father, Traditional, Ekiti 1

In Community B (Ekiti) where some families used faith-based (church owned) maternities for the delivery of their children, one mother's confidence in the birth attendants was tied to her religious beliefs.

'[The faith-based maternity home] was closer to us and we had confidence in it. People did not have confidence in the hospital there because it is very far from the community. With the power of prayer, we just believed that all will be well with us'.

Mother, Traditional, Ekiti 4 


\section{Health Workers}

Most 'health workers' interviewed share similar beliefs about the clitoris as parents, and most of them had FGM/C performed on their own daughters. Although only one 'health worker' interviewed admitted to current FGM/C practice, all 'health workers' mentioned that when they practiced, community members, fellow health workers, or their health facilities were aware of their practice. They typically learned the practice from other health workers, often senior colleagues.

So who taught you how to do it?

'My late director' [referring to the director in the facility where she worked previously] Was your director a medical doctor?

'Yes'. Health Worker, Delta 7

Can you explain to us why people practice circumcision?

'If you don't circumcise girls, like in these our Oguta communities, when she reaches the age of puberty and has her first sexual experience, she will feel somehow, wanting to have sex with the man always. The clitoris will make her have the urge for sex again and again. That is why the clitoris was cut off before government stopped the practice...Another demerit is that when a child goes to urinate, you will see an overlapping clitoris when she stoops down, it's not good. Understand? That is why FGM is practiced'.

It's done to...

'To beautify the looks of the vagina'

Health Worker, Imo 8

Most 'health workers' reported learning the practice from other cutters, with no formal training.

So when these your daughters were circumcised, were you the cutter?

'No. Someone handled the cutting of my first daughter. Even we were not taught how to do circumcision where I trained. So I learnt how to do it in 1994, when my first daughter was cut. I held my daughter for her to cut her, and I learnt it from her, together with the removal of the tongue ligament'.

You learnt from her? Was the person a traditional cutter? Or?

'No, she was a nurse'.

So you cut your second daughter yourself?

'Yeah, I did the cutting.'

Health Worker, Imo 8

When questioned about their colleagues' perception of their FGM/C practice, some 'health workers' implied it was an accepted practice for health workers until fairly recently when they had been told to cease the practice. One 'health worker' was called on to cut her colleague's daughter and in the process taught her colleague how to perform FGM/C. 'Health workers' spoke of colleagues refusing to practice FGM/C because of fear of girls or women experiencing lifethreatening complications and FGM/C being against their Christian beliefs. It did not appear that colleagues who do not practice FGM/C strongly objected to health workers who do. One "health worker' mentioned that her non-cutting colleagues only warned health workers not to practice, and another believed that non-cutting colleagues actually admired the courage of health workers who cut.

'When it gets to that time...our juniors in our place of work, when we want to do it, if they are on night duty and we want to perform FGM/C, they watch the operation'.

What do your colleagues think about you or other health workers performing FGM/C?

'Our thought at that time was that, it was-ah-an acceptable culture. It is only now that they said it should not be done again'.

Are the hospital authorities aware that FGM/C takes place right in the hospital?

'From time immemorial'.

Health Worker, Ekiti 10 
Fees 'health workers' charged were dependent upon many factors. According to 'health workers', charges could be based upon a personal relationship between the two parties, whether the health worker delivered the child, or by what the parents could afford. 'Health workers' reported charging parents 3,000 NGN or less. One 'health worker' charged the cost of her transportation from the client's community to her place of practice and performed the procedure for free when she delivered the child.

The procedure all 'health workers' described was essentially similar with slight variations. 'Health workers' interviewed mentioned the following essential supplies: antiseptic, artery forceps, surgical scissors or blade, cotton wool, and antibiotics. They described the steps as: using an antiseptic to clean the area, clamping the tissue with forceps, cutting the tissue with scissors or a surgical blade, applying pressure with cotton wool to control bleeding, cleaning the area again with an antiseptic, and applying an oil or Vaseline. Some 'health workers' mentioned administering pain relief and prescribing antibiotics. One 'health worker' described the procedure in the following steps:

'Inside the circumcision set, we have one circumcision scissors, we have....artery forceps. Then we still have three mosquito forceps...

'From inside [the circumcision set] we make use of the scissors...

'You hold it and you cut...

'We just cut off the clitoris...the way you cut something...

'We open the vagina [labia majora], and then you can cut the clitoris off...

'We don't cut the adjoining tissue to the clitoris. We cut the clitoris only...

'After cutting it...There was one injection we normally use then...It's either Dio-kay Injection [unsure of what it is called]...During the process, when you want to carry out this circumcision, it kills the pains...

'After cutting...you clean it with spirit [Methylated spirit]...

'There is this oil they use there...You apply it on the surface...

'We administer antibiotics. If it's for adults we give them Flagyl, vitamin C, PCM

[Paracetamol], and Ampiclox'.

Health Worker, Delta 3

When questioned about what type of FGM/C they performed, most 'health workers' (only one from Community C, Imo state, refused to answer this question) described removal of part or all of the clitoris (Type I), which they felt was a minor cut.

'They take the surface of the clitoris and cut a small portion out of it, finish...Ah! It is not a major cut, you just trim...you just trim and it is finished'.

Health Worker, Ekiti 10

'I just cut the clitoris and then place the patient on [a] hot seat bath'. Health Worker, Delta 7

Across all study communities, none of the 'health workers' had experienced any complications with the procedures they had conducted. However, they admitted to being aware of incidences of bleeding with procedures done by others, both health workers and traditional cutters, explaining that it was likely that the practitioner had made a cut that was too deep. Two 'health workers' also mentioned knowing about complications in labour and delivery related to FGM/C. Only one 'health worker' mentioned sexual dysfunction as a negative consequence of FGM/C and none mentioned the possible negative psychological impacts of FGM/C.

'As I learnt, the base of the clitoris should not be cut because there is a vein that passes through there. Someone who doesn't know about this fact will eventually cut the vein, and the result is usually uncontrolled bleeding. That is why bleeding kills some infants. Do you understand? So unless you know about the procedure or the use of artery forceps to hold the base of the clitoris before cutting, cut and tie afterwards, then you can control the bleeding. Otherwise, it would be too late before you will be able to control the bleeding.

'Secondly, after circumcision the wound dries and heals then forms a scar on the base of the clitoris. This turns to a problem for a primigravidal mother. In this scenario, episiotomy 
becomes inevitable. Here razor or scissors is used to lacerate the vulva to enable the head of the baby to come out, or the use of hot injection (maybe through drip) to facilitate delivery. Do you understand? So female circumcision has been causing problem through excessive bleeding. The way it was done before government stopped the practice about five to six years now was that the base of the clitoris which is assumed to be the head [isi agama, according to "health worker"] should not be cut rather tissues around the clitoris should be trimmed off. This very procedure will allow the girl to have free child birth without episiotomy due to the expansion of the clitoris during labour...Government stopped health workers from involving in this practice because of the excessive bleeding in infants'.

Health Worker, Imo 8

\section{Rationales of Health Workers}

'Health workers' were asked why they or other health workers provide FGM/C services to families. Most 'health workers' said they provided FGM/C because they shared their communities' FGM/C beliefs. One 'health worker' in Community C (Imo state) learned how to perform FGM/C from a colleague, who cut her first daughter, then subsequently she cut her second daughter herself.

The youngest 'health worker', who claimed to no longer practice FGM/C, explained that it was a practice done openly at the clinic where she worked, and she learned to have a sense of belonging, out of curiosity, and the thrill of being able to know how to do the procedure. She also mentioned that some others caved into pressure possibly because they were afraid that parents they refused would spread rumors of their professional incompetence within the community.

'Actually, why I did it...I wanted to try my hands to see if I would be able to... Other nurses
were with me when I did it the first day...just training me. It's kind of to learn something.
That's why I did it... because I met them doing it, and I wanted to participate. Where I was
working they were into it. All I wanted was to get some experience. I did it on only two
occasions and never did it again, up till now. I don't even circumcise males because I am
afraid of complications. I don't want the person to bleed...But some persons, the
pressure...if they come to you, if you did not perform it for them, you know our locality here,
some might carry it outside saying that the nurse is not professional enough in carrying
out the work, people may go out and peddle news around, that so and so person does not
know her job'.
Health Worker, Delta 3

One 'health worker' admitted that though she did not support the practice of FGM/C, she performed FGM/C because patients demanded for it and it was also a source of income. She also believed that other health workers perform FGM/C for financial reasons. Another 'health worker' felt FGM/C was practiced by health workers because parents insist and plead, and that the law criminalising the practice was not being enforced. The same 'health worker' explained that health workers also perform FGM/C to mitigate the health risks of traditional cutters. Some 'health workers' viewed FGM/C as part of their professional role and expertise.

And people know that [FGM/C] is what you do?

'Every nurse does it [FGM/C] if she is well trained'.

Health Worker, Imo 5

Do you know of other health workers who still perform female circumcision?

'Actually, if you ask them, they will say they are not doing it'.

But you know they still do it?

'Yes'.

Why do you think they do it?

'Like what I explained earlier, the lady that I spoke to said it was her job'.

That it's her job?

'Yes. That she cannot go to school, study something and suddenly she is asked to stop her practice'.

Health Worker, Delta 3 


\section{Abandonment}

\section{Awareness of anti-FGM/C campaigns}

Overall, more interviewees reported having heard of the campaign against FGM/C than those who had not. This was the case in Community B (Ekiti) and Community C (Imo), but in Community A (Delta) participants who endorsed awareness of any campaigns against FGM/C were equal to those with no awareness. Awareness of anti-FGM/C campaigns was the least in Community D (Kaduna). In Community A and Community D, two parents who were aware of abandonment interventions described interventions that did not appear indigenous to their communities.

In all study states except Kaduna (Community D), the government has provisions criminalising FGM/C. Most interviewees in Ekiti and Delta states had heard about criminalisation of FGM/C and believed that others knew about the law. In Community A (Delta state), one father admitted that even though the community members were aware of the criminalisation of FGM/C, they continued the practice because they felt what they were doing was beneficial to their daughters.

'Well, you know we are aware of some of these things, so if I tell you that I am not aware it means I am lying. There are some things we know are not good. We know the government prohibits them. For example, drivers know they should have their driver's license when driving, but if your daughter is sick and needs to be taken to the hospital and you know how to drive and your friend decides to lend you his car, you cannot say because you don't have a driver's license you won't drive your child to the hospital, so that is what I am implying'.

Father, Medicalised, Delta 6

\section{Personal willingness and community readiness to abandon FGM/C}

Among parents and 'health workers', some interviewees were personally willing to abandon the practice or advocate against it. As described earlier, no 'health workers' except one admitted to current FGM/C practice. Some parents claimed to have not cut their younger daughters and expressed regret at cutting older daughters. Reasons for their willingness to abandon included fear of government policy, increased awareness and fear of complications, and exposure to abandonment messages.

Have you ever heard that the government wants to stop the practice of female circumcision? Have you ever heard about it?

'Yes, and that is why I did not circumcise this one' [pointing to the baby in her arms].

O.K.

'That was why I did not circumcise this one'.

In your opinion do you think that it is a good thing? Should it be stopped? Or...

'Yes it is a very good thing, a very good thing [that it should be stopped]. They should stop it, because I regret cutting my first daughter. She is not happy about it. She knows a little; she's not happy about it'.

A four year old child? What does she know?

'She knows a little, she knows a little. Let me put it that way. Because there is a woman whose daughter has grown. My neighbor told me that her daughter has been scolding her for having her cut and she said to me that someday my own daughter will do the same to me. This is because they are taught about all these things at school and she may come asking to find out'.

Mother, Medicalised, Imo 1

Varied views were presented when participants were asked if their communities would ever end FGM/C. Some parents, who were more pessimistic about the possibility of community abandonment, felt that girls and women needed to be sexually controlled, so FGM/C would have to continue. Others believed the practice was too old to die quickly, arguing that it was a cultural practice that would take time to fade away, as it had been practiced since time immemorial. Other interviewees felt that that the practice could end if people were informed about its dangers. They 
also needed to be reassured that the negative consequences they believed would occur if girls and women were left uncut would not happen. Some interviewees were more confident that the practice would stop with the right interventions. One father recommended that abandonment would require offering communities another way to limit women's sexual desires.

Are you aware that people are campaigning seriously against this female circumcision?

'Yes, I have the awareness'.

So what do you think about it, is it a good thing?

'Left for me I would have advised that they should stop it, but if you are stopping it, I feel...because if you want to tell any of your children not to eat beans you have to make provision for that thing you want your child to eat. So if you are telling your child not to eat beans and may be you want him to eat rice and you cannot afford the rice then they will continue eating the beans because they don't want to die at least until they see the rice'.

So what do you mean by this, please break it down for me to understand?

'What I mean is that it is good they stop it, I will advise they stop it but if they are stopping it the government should introduce new measures with professional bodies, because I believe if government cannot bring professionals no other persons can do it. They should introduce new methods of making women not to have sexual urge'.

So they must stop the sexual urge of women?

'Yes'.

They cannot just stop female circumcision?

'Yes, that is the problem, the sexual urge is the problem'. Father, Medicalised, Delta 6

\section{Steps to ensure abandonment}

Participants were asked to detail the steps those advocating against FGM/C practice need to take to ensure abandonment. Participants' responses can be grouped into three categories: instructional, consensus building, and punitive measures.

Many participants believed that abandonment of FGM/C could be achieved through community sensitisation, especially on the dangers of the practice. They also stated that it was important to involve key influencers in communities, specifically traditional rulers, and community and religious leaders, in sensitisation activities. In addition to harnessing the influence of community leaders, some participants in Community A (Delta state) emphasised the importance of sensitisation activities among families and advocating with older women in communities. Radio, television, movies, and health talks at health centres, churches, and markets were also mentioned as a useful means for disseminating FGM/C abandonment messages.

What do you think can be done to stop female circumcision?

'In my opinion, I think that the awareness should start with the ruler of the community, the women leaders and the nurses at the health center and at the general hospitals. Tell them to please stop this. They should be informed about the effects of female circumcision'.

Mother, Medicalised, Imo 1

What do you think all of us can do collectively to end the cutting of girls in Ekiti and IkereEkiti community?

'In Ikere, at least, we have to orientate our people, let them know...the disadvantage in cutting...that it is a criminal offence, that it is not good. If people are aware of that, I believe they will surely change from that old style. And they can easily change and stop cutting'.

Father, Traditional, Ekiti 1

Sensitisation of health workers, traditional cutters, and TBAs was also thought necessary for FGM/C abandonment. One parent felt that sensitisation efforts should reach health workers, 
traditional cutters, and TBAs because he believed a diminished supply of potential cutters would also inhibit demand.

What are the best ways or processes to end FGM/C in this community?

'The way I think we can follow, as I said earlier on...we should call the health workers, the traditional worshippers and the traditional birth attendants together, for a seminar. If they are called together for seminar, they will know the risks... and consequences...If parents go to hospitals and they are turned down, and they go to traditional cutters and they also refuse to do it for them, due to the risks... and same happens at the traditional birth attendants, where else will they go to? They will be forced to have a rethink...that there are dangers involved. But if we don't call them together for the seminar, and government is only fighting against it in the hospitals, some people will go the traditional cutters, because they will still want to observe the culture. But if the three are united, and they are not doing it again, nobody will do it, and it will be forgotten'. Father, Medicalised, Ekiti 2

Some interviewees believed abandonment could be achieved if consensus building on the harmful effects of FGM/C occurred with community leaders and community members themselves.

Let us imagine that this female circumcision will end. Can you give a step by step advice someone like us can adopt to stop it? Advise us.

'In that case, before you come, you meet the chairman of the community or the president of the community, you announce the mission of coming into the community. He will call the women together, or some few key women in the village together, that somebody came to our town. He wants to educate you about female circumcision, the disadvantage of it, how you people can leave that female circumcision. You tell them and your analysis is very O.K. with them; they will leave it. You tell them the disadvantage of it; they will stop'.

Father, Medicalised, Delta 5

\section{What can be done to make people stop female circumcision?}

'That is if everybody agrees to stop it. Well before it can be stopped, there has to be an explanation why female circumcision should be stopped. You understand? Then after explaining, they have to agree knowing the consequences'. Mother, Medicalised, Imo 2

What do you think can be done in order to end female circumcision in this community?

'That one is left for God to handle... and whosoever agrees to abandon the practice, because even if we agree to stop, we can go out publicizing it or telling people to stop... but if there is unity and understanding, it will come to a stop'. Mother, Traditional, Kaduna

Some interviewees felt strongly that pronouncements and laws banning FGM/C should be utilised and enforced more firmly by the government, to hasten abandonment. One father warned that communities would not comply with anti-FGM/C laws for which they do not understand the rationale.

So in your opinion, what do you think the government can do to stop female circumcision? 'In my opinion if the government finds anybody doing it they can get the person arrested with the police. Then they should also go to the place where the child was circumcised and get the person who carried it out arrested with the police too. By the time two or three people are arrested, others will learn from them'.

Mother, Medicalised, Imo 4

'If you bring a law without explaining the reason behind the law, you know our people are quick to sense oppression so they may not obey. But when you give them a justification for the law, they will always concur and accept it'.

Father, Medicalised, Delta 6

\section{Role of health workers in abandonment}

In the study communities, health workers had both positive and negative influences on abandonment. Several mothers, especially in Imo state, mentioned that health workers in government health facilities actively discouraged parents from cutting their daughters and ensured that cutting did not occur in their facilities. On the other hand, a mother in Ekiti described how she 
was approached by nurses at the hospital where she delivered her baby, who mentioned that FGM/C was one of the services they could offer, and this played a role in her decision to cut her daughter. Another Ekiti mother expressed concern that health workers might be undermining abandonment messages through their contradictory actions.

'Even those nurses preaching against it are practicing it in secret on their children, grandchildren and even others'.

So because some nurses are practicing it, it means there are some benefits in it which you think your own daughters would be deprived of?

'Yes, because I have once questioned that my friend and I asked her; why is your mum cutting your female children when it is the nurses that have been telling us to stop cutting our own daughters? She just laughed and said to me, "should her children not be cut?" And that a male must be circumcised, a female must be cut. That is what she usually tells me and I will reply that, and you people will be sensitising others to abandon FGM/C. For example, it is like the issue of infant formula, they will tell us not to bottle feed our children but to do exclusive breast feeding for the first six months of the childbirth. But when a nurse advises her own daughter to breastfeed for only two weeks and then turns around to tell us poor people to breastfeed for six months... Ha! Since I saw such deceit, I refused to do what they told me'.

Mother, Traditional, Ekiti 4 


\section{Discussion}

In our study communities, FGM/C is a cultural practice fueled and sustained by myths and misconceptions about the clitoris and its effect on maternal and newborn health, women's genital appearance and hygiene, and sexual behaviour, similar to other studies (Alo and Gbadebo 2011, Iliyasu et al 2012, Ahanonu and Victor 2014, Ashimi and Amole 2015, Ashimi et al 2015). These myths and misconceptions, which often stigmatise uncut women, are deeply embedded in participants' senses of tradition and culture, and reflect gendered realities in which marriage and childbearing are women's paramount achievements, sexual restraint is their purview, while sexual pleasure is a male prerogative, and men are the final decision-makers for matters involving women's bodies with women as the enforcers of such decisions.

The general perception of parents is that FGM/C, whether medicalised or traditional, is a minor procedure that heals quickly and has significant benefits for their daughters' future well-being as wives and mothers. Nonetheless, some parents chose medicalised FGM/C based upon the belief they would receive superior care at health facilities or from health workers, perceiving health workers as more careful, knowledgeable, skilled, and hygienic. Parents also believe health workers have more options than traditional cutters, for adequately caring for their daughters in emergency situations or complications, but these concerns do not originate from knowledgeability or even fear of FGM/C complications, instead they are based more upon general trust of health workers for health matters. This is in contrast to Modrek and Sieverding's findings among Egyptian mothers, who wanted FGM/C from doctors to mitigate perceived risks (acute adverse effects like hemorrhage) (2016). Some who sought traditional cutters believe that traditional cutters are more highly qualified, however, implying that medicalisation is influenced by parental levels of trust in the formal health system.

Parents' impression of FGM/C as a benign procedure may also be due to their limited knowledge of what is truly done during the procedure. Ashimi et al (2015), in their study of FGM/C among 215 female infants in northern Nigeria, found little correlation between what type of FGM/C was reported by an infant's mother and the type of FGM/C investigators observed, with correlation in only 7.4 percent of the infants, no correlation in 51.7 percent, and in 40.9 percent the nature of what was done was unknown to the mothers. Men's absence from the mechanics of the process and the silence around FGM/C in communities also makes it less likely that men, the final decisionmakers, are fully aware of the implications of FGM/C. Similarly, Kaplan et al (2013) found that 72 percent of Gambian men they interviewed did not know FGM/C had a negative impact on health. Interviews with men in Northern Sudan, where infibulation (Type III FGM/C) is more prevalent, revealed that they did not accurately understand $\mathrm{FGM} / \mathrm{C}$, as it was not until they were newly married that they experienced the consequences of their wives' FGM/C (Berggren, Ahmed et al 2006). Educating community members, especially men and boys, about FGM/C and its complications, and engaging them in community dialogues (with women and girls) on FGM/C is necessary for abandonment. In their intervention study, Asekun-Olarinmoye and Amusan (2008) demonstrated that health education sessions decreased Nigerian men's pro-FGM/C attitudes.

Parents' limited knowledge of FGM/C complications, and the extent of the procedure, early ages at cutting, and less extensive types of cutting, are likely contributing to the perception and attitude that the practice is not harmful to women and girls, and may, in these study communities, make it harder to eliminate than when health and psychosocial impacts are more pronounced. Type I FGM/C (clitoridectomy) appears to be the primary form of FGM/C in these study communities. Typically, the amount of genital tissue cut generally increases from type I to III, although there are exceptions (WHO 2017). Although all forms of FGM/C carry health risks, risks decrease as the practice's severity decreases, which are directly linked to the extent of cutting (WHO 2017). 
Women and girls in the study communities may be experiencing less complications than those in communities where types II and III are more prevalent.

Additionally, an early age at cutting could be contributing to parents' poor awareness of complications, similar to the findings of Lawani et al (2013) and the 2013 NDHS, as infants and young girls are unable to articulate their experiences, and many complications such as sexual dysfunction and problems with childbirth are not experienced until adulthood. Women, potentially not even cognisant of their FGM/C status, due to their cutting in early childhood, may not necessarily connect negative adult experiences to the practice of FGM/C. Another contributor to lack of awareness of complications could be the silence surrounding FGM/C practice, with FGM/C only discreetly discussed among female peers. Interestingly, no participant (including health workers and parents) mentioned any psychological impact of FGM/C, which could also be due to the early age at cutting, with infants unable to share the trauma of the experience in addition to limited opportunities for girls or women to discuss the psychological and sexual impacts of FGM/C.

Many parents and health workers are aware of the possible impact of FGM/C on women's sexuality, as all but two participants (one father and one health worker) spoke of it as a benefit. To them, curtailing women's sexual desires prevents promiscuity and marital infidelity. Although, Mpofu et al (2016), in their study of FGM/C's relation to sexual behaviour in Kenya and Nigeria, found no association between FGM/C and age at first intercourse, as well as number of lifetime sexual partners. In addition to actively sensitising families and communities on complications attributed to FGM/C, it is important that abandonment interventions in Nigeria facilitate community dialogues on sexuality and women's sexual rights/bodily integrity in order to change prevailing societal norms that encourage the problematisation and suppression of women's sexual desires and pleasure. These dialogues can be integrated into existing community platforms like women's, men's, and youth groups typically present in many communities across Nigeria.

In most study communities, FGM/C is a procedure done in infancy, a custom that follows childbirth, similar to male circumcision. For many parents, the provider (health worker or TBA) who assisted their delivery was also the person who "circumcised" their daughter. Some health workers and facilities bundle the costs of FGM/C in their labour and delivery package, serving as a kind of "one stop shop". This may also be one of the factors contributing to the significantly lower prevalence of medicalised FGM/C compared to traditional FGM/C, as the use of skilled birth attendants during delivery is very low in Nigeria. NDHS 2013 found that 38.1 percent of women were delivered by skilled health providers (doctor, nurse, midwife, auxiliary nurse/midwife). Interventions in Nigeria are currently aimed at increasing use of skilled birth attendants. Such increases in skilled health provider use for labour and delivery, without adequate anti-medicalisation interventions, may inadvertently increase medicalised FGM/C in communities where FGM/C is performed in infancy.

In one study community, in Ekiti, lines are blurred between the traditional and medical, with churchbased maternities performing FGM/C. These church-based maternities typically use personnel who are either TBAs or health workers. Women obtain obstetric services from church-based clinics for spiritual protection against satanic attacks for safe delivery, fear of caesarean sections, limited financial resources, health workers' disrespect or abuse, convenience, religious faith, or prior delivery in a church-based clinic (Orji et al 2001, Udoma et al 2008). This entanglement of the traditional, medical, and spiritual is problematic in highly traditional and religious communities, as it has the potential to further entrench social norms fuelling the practice. This needs to be appropriately addressed by active engagement and sensitisation with faith-based providers of obstetric services.

Most health workers engaging in FGM/C do so because they share the same FGM/C beliefs as their fellow community members, evinced by the fact that four out of the five health workers with daughters had also cut their daughters. Health workers also mentioned parental pressure, the 
fulfillment of their professional roles, harm reduction for girls and women, and additional income as reasons for engaging in the practice. Onuh et al (2006) found similar reasons for FGM/C practice among Nigerian nurses. FGM/C was learned from and not hidden from fellow health workers. Fellow health workers are a strong reference group for health workers. Learning from colleagues or supervisors could legitimise the practice for many health workers. Health workers who had colleagues either afraid to perform the practice or with personal objections do not perceive that their non-cutting colleagues viewed them negatively for engaging in a practice that is, in fact, risky and harmful to patients. It appears that informal professional norms are contrary to current legal norms.

Health workers are important community role models. They have a significant role to play in abandonment efforts, which can either be promotive or inhibitory, as demonstrated by study participants' experiences. It is important that health workers are educated and empowered to strongly advocate for abandonment not only among patients but also among fellow health workers. Interventions utilising health workers as agents of change should not only view health workers according to their professional roles but also recognise that they are community members embedded in the social beliefs and norms that sustain FGM/C within their communities. Such interventions should involve a values clarification process enabling health workers to examine their belief systems, as both health workers and community members, to prevent their acting in contradiction to FGM/C abandonment messages and leading to mistrust of these messages among community members.

Income generation does not appear to be a major motivator for FGM/C among health workers interviewed in our study. Nevertheless, one health worker did admit to providing FGM/C to patients, despite personally objecting to the practice, because of the financial benefit. The fact that some health workers who perform FGM/C might do so as a source of additional income is worrisome in the current context of an economic recession, with health workers poorly and inconsistently compensated. This may pose a challenge for policies and programmes aimed at discouraging medicalisation. Policymakers and program implementers intervening with medicalisation should leverage or build upon existing work advocating for adequate investments in human resources for health in Nigeria.

\section{Conclusion}

The shift towards medicalisation is occurring in some Nigerian communities. Families in these communities still hold strongly to societal beliefs and expectations sustaining FGM/C practice and choose medicalisation due to their trust in the quality of services of health workers and health facilities and not out of being knowledgeable or afraid of health complications. Families still view FGM/C as a minor, highly beneficial, and essential procedure with minimal negative effects, which is detrimental to current abandonment efforts. This perception may be due to minimal public discussion of $F G M / C$, early ages for cutting, the predominant type of $F G M / C$ practiced (clitoridectomy), limited knowledge of the extent of the FGM/C procedure and its complications, and possibly fewer FGM/C complications in their communities than in those practicing more extensive types of cutting.

Health workers respond to families' demands mostly because they also share the same FGM/C beliefs. Some health workers believe that providing the service to families limits life-threatening or other serious complications associated with $F G M / C$, especially since families will still go to traditional cutters if they turn them away. Others welcome the additional income. Despite this shift towards medicalisation, it appears that abandonment messages and interventions are reaching 
some high prevalence communities, and families and health workers are beginning to abandon FGM/C practice.

To maintain and improve upon the gains in eradicating $\mathrm{FGM} / \mathrm{C}$, including the prevention of medicalisation, we recommend the Nigerian government and implementers of $\mathrm{FGM} / \mathrm{C}$ abandonment programs and interventions:

- Continuously educate community members on the myths, misconceptions, and harms associated with $\mathrm{FGM} / \mathrm{C}$, including medicalisation, through diverse community and target group platforms and channels

- Intensify FGM/C abandonment interventions, especially in high prevalence communities, to ensure adequate reach and coverage of messages

- Provide further community dialogue opportunities on gender equality, FGM/C, and sexuality

- Ensure male involvement in community dialogues on FGM/C, and engage men in FGM/C abandonment interventions

- Develop FGM/C abandonment messages that explicitly discourage medicalisation and all other forms of FGM/C practice

- Engage health workers, health facilities, traditional cutters, TBAs, church-based maternities, and community key influencers (traditional rulers, religious leaders, political leaders, older women, etc.) in FGM/C abandonment interventions.

- Conduct values clarification exercises with anti-FGM/C champions including health workers to ensure their behaviours are not contradictory to the messages they promote

- Sensitise all cadres of health care workers during pre-service and in-service trainings

- Utilise health workers and health worker professional bodies to advocate for the abandonment of FGM/C practice among health workers

- Implement studies aimed at improving our understanding of the effectiveness of legislation and policy reform on behaviour change for FGM/C, including medicalisation.

\section{Limitations}

Heath worker authenticity: We cannot guarantee that the parents interviewed who utilised health workers for their daughters' FGM/C engaged genuine health workers. In Nigeria, community members often mistakenly view any individual associated with health facilities or possessing any health paraphernalia (white coats, health equipment) as a health worker. Individuals do misrepresent themselves as trained health workers and practice in Nigerian communities.

Health worker sample: Although we attempted to sample from communities from all four geopolitical zones in Nigeria, the small number of health workers interviewed does not ensure we reached saturation with our interviews. We were also unable to sample from different health worker cadres, so we may not have been able to capture the experiences and perspectives of different cadres. We did not verify the licenses and registration status of health workers we interviewed. In a context like Nigeria, where people have been caught practicing in communities and facilities without appropriate qualifications, we cannot guarantee we interviewed appropriately trained health workers exclusively. Health workers were identified by key informants in communities and by parents who had used them for FGM/C.

Parent sample: Given the sensitive nature of $F G M / C$, it was important to recruit parents through trusted community based organisations (CBOs) knowledgeable about the practice. Although we encouraged the $\mathrm{CBO}$ to recruit widely, we cannot eliminate the possibility that our study sample 
was recruited from individuals who had interfaced with the CBOs' previous activities and might be more knowledgeable about FGM/C as a result.

Criminalisation of FGM/C: Despite measures taken to gain study participants' trust, including rapid anonymisation, strict assurances of confidentiality, and no evidence of FGM/C prosecutions in Nigeria prior to study data collection, the risk of prosecution due to criminalisation of $F G M / C$ in three of the study communities may have altered participant responses. In Imo state, data collection occurred in the same week Imo's First Lady launched an anti-FGM/C campaign.

Time and budgetary constraints: In some communities we may not have been able to mobilise participants as thoroughly and reach saturation. In Kaduna, where it was challenging to find indigenous families choosing medicalisation and health workers providing medicalised FGM/C services, with more time and resources it could have been possible to find and interview more appropriate respondents, which would have resulted in richer data for analysis. 


\section{References}

Adekanle, AD, Al Isawumi, AS Adeyemi. 2011. Health workers' knowledge of and experience with female genital cutting in Southwestern, Nigeria. Sierra Leone J Biomed Res 3(2): 84-88.

Adeloye, D, RA David, AA Olaogun et al. 2017. Health workforce and governance: crises in Nigeria. Human Resources for Health 15(32).

Ahanonu, EL and O Victor. 2014. Mothers' perceptions of female genital mutilation. Health Education Research 29(4): 683-689.

Almroth, L, H Bedri, S El Musharaf et al. 2005. Urogenital complications among girls with genital mutilation: a hospital-based study in Khartoum. Afr J Reprod Health 9: 118-124.

Alo, OA, and B Gbadebo. 2011. Intergenerational attitude changes regarding female genital cutting in Nigeria. Journal of Women's Health 20(11): 1655-1661.

Ashimi, AO and TG Amole. 2015. Perception and attitude of pregnant women in a rural community north-west Nigeria to female genital mutilation. Archives of Gynecology and Obstetrics 291(3): 695-700.

Ashimi, AO, TG Amole, Z lliyasu. 2015. Prevalence and predictors of female genital mutilation among infants in a semi urban community in northern Nigeria. Sexual and Reproductive Healthcare 6: 243-248.

Askew, I, T Chaiban, B Kalasa, P Sen. 2016. A repeat call for complete abandonment of FGM. Journal of Medical Ethics 42, 619-620.

Behrendt, A and S Moritz. 2005. Posttraumatic stress disorder and memory problems after female genital mutilation. American Journal of Psychiatry 162: 1000-1002.

Berg, RC, V Underland, J Odgaard-Jensen et al. 2014. Effects of female genital cutting on physical health outcomes: a systematic review and metaanalysis. BMJ Open 4(11).

Bicchieri, C. 2006.The Grammar of Society: The Nature and Dynamics of Social Norms. New York: Cambridge University Press.

Daly, C and M Carson. 2016. www.theguardian.com/society/2016/oct/11/fgm-nigeria-20-millionwomen-and-girls-undergone-female-genital-mutilation

Dare, FO, VO Oboro, SO Fadiora, EO Orji, AO Sule-Odu, TO Olabode. 2004. Female genital mutilation: an analysis of 522 cases in South-Western Nigeria. Journal of Obstetrics and Gynaecology 24: 281-283.

Elnashar, RA and R Abdelhady. 2007. The impact of female genital cutting on health of newly married women. International Journal of Gynecology and Obstetrics 97: 238-244.

Ezenyeaku, C, T Okeke, C Chigbu, L Ikeako. 2011. Survey of Women's Opinions on Female Genital Mutilation (FGM) in Southeast Nigeria: Study of Patients Attending Antenatal Clinic. Annals of Medical and Health Science Research 1(1): 15-20.

Iliyasu, Z, IS Abubakar, HS Galadanci, F Haruna, MH Aliyu. 2012. Predictors of female genital cutting among university students in northern Nigeria. Journal of Obstetrics and Gynaecology 32(4): 387-92.

Kaplan, A, B Cham, L Njie, A Seixas, S Blanco, M Utzet. 2013. Female genital mutilation/cutting: the secret world of women as seen by men. Obstet Gynecol Int, Article ID 643780. 
Knight, R, A Hotchin, C Bayly, S Grover. 1999. Female genital mutilation-experience of The Royal Women's Hospital, Melbourne. Australia New Zealand Journal of Obstetrics and Gynaecology 39: 50-54.

Language and Culture. Official Website of the Government of Ekiti State, Nigeria. Ekiti State Bureau of ICT. http://ekitistate.gov.ng/about-ekiti/overview.

Lawani, L, A Onyebuchi, A lyoke, N Okeke. 2014. Female genital mutilation and efforts to achieve Millennium Development Goals 3, 4, and 5 in southeast Nigeria. International Journal of Gynecology and Obstetrics 125: 125-128.

Mackie, G, F Moneti, H Shakya, E Denny. 2015. What are Social Norms? How are they measured? UNICEF \& UCSD.

Mandara, MU. 2000. Female Genital Cutting in Nigeria: Views of Nigerian Doctors on the Medicalisation Debate. In B Shell-Duncan and Y Hernlund (eds.), Female "Circumcision" in Africa: Culture, Controversy and Change (95-107). Boulder, CO: Lynne Rienner Publishers, Inc.

Modrek, S and M Sieverding. 2016. Mother, Daughter, Doctor: Medical Professionals and Mothers' Decision Making About Female Genital Cutting in Egypt. International Perspectives on Sexual and Reproductive Health 42(2): 81-92.

National Population Commission. 2009. 2006 Population and Housing Census of the Federal Republic of Nigeria Priority Tables (Volume 1).

National Population Commission (NPC) [Nigeria] and ICF International. 2014. Nigeria Demographic and Health Survey 2013. Abuja, Nigeria and Rockville, Maryland, USA: NPC and ICF International.

Njue, C, and I Askew. 2004. Medicalisation of female genital cutting among the Abagusii in Nyanza Province, Kenya. Washington, DC, Population Council Frontiers in Reproductive Health.

Onuh, SO, GO Igberase, JOU Umeora et al. 2006. Female genital mutilation: knowledge, attitude and practice among nurses. Journal of the National Medical Association 98(3): 409-414.

Orji, EO, FO Dare, ON Makinde, OB Fasubaa. 2001. Determinants of mission house delivery among booked patients in a Nigerian teaching hospital. J Obstet Gynaecol 21(5): 482-484.

Orubuloye, IO, P Caldwell, J Caldwell. 2000. Female "circumcision" among the Yoruba of Southwestern Nigeria: The beginning of change. In B Shell-Duncan \& Y Hernlund (eds), Female "Circumcision" in Africa: Culture, Controversy and Change (73-94). Boulder, CO: Lynne Rienner Publishers, Inc.

Osuizigbo, L. 2016. Nigeria and the challenge of Ending Female Genital Mutilation www.premiumtimesng.com/news/top-news/218553-nigeria-challenge-ending-female-genital$\underline{\text { mutilation.html }}$

Ras-Work, B. 2009. Legislation to Address the Issue of Female Genital Mutilation (FGM). Addis Ababa: United Nations. www.un.org/womenwatch/daw/egm/vaw legislation 2009/Expert\%20Paper\%20EGMGPLHP \%20 Berhane\%20Ras-Work\%20revised .pdf

Shell-Duncan, B. 2001. The medicalisation of female "circumcision": harm reduction or promotion of a dangerous practice? Social Science \& Medicine 52(2001): 1013-1028. 
Shell-Duncan, B, Y Hernlund, K Wander, A Moreau. 2010. Contingency and Change in the Practice of Female Genital Cutting: Dynamics of Decision Making in Senegambia, Summary Report on the WHO/NSF Multicountry Study on Behaviour Change.

Shell-Duncan, B, K Wander, Y Hernlund, A Moreau. 2011. Dynamics of change in the practice of female genital cutting in Senegambia: Testing predictions of social convention theory. Social Science and Medicine 73: 1275-1283.

Shell-Duncan, B, R Naik, C Feldman-Jacobs. 2015. A State- of-the-Art Synthesis on Female Genital Mutilation/Cutting: What do we know in 2015? Evidence to End FGM/C Programme Report. New York: Population Council

Udoma, EJ, AD Ekanem, AM Abasiattai, EA Bassey. 2008. Reasons for preference of delivery in spiritual church based clinics by women of south-south Nigeria. Niger J Clin Pract 11(2): 100103.

Ugboma, HA, Cl Akani, S Babatunde. 2004. Prevalence and medicalisation of female genital mutilation. Nigerian Journal of Medicine 13(3): 250-253.

United Nations General Assembly. 2012. Intensifying global efforts for the elimination of female genital mutilations. www.un.org/ga/search/view doc.asp?symbol=A/RES/67/146

UNICEF. Female Genital Mutilation/Cutting: A Global Concern. http://data.unicef.org/wpcontent/uploads/2016/04/FGMC-2016-brochure 250.pdf

Umar, AS and OM Oche. 2014. Medicalisation of female genital mutilation among professional health care workers in a referral hospital, north-western Nigeria. Journal of Reproductive Biology and Health 2(2).

Welcome, MO. 2011. The Nigerian health care system: Need for integrating adequate medical intelligence and surveillance systems. J Pharm Bioallied Sci. 3(4): 470-478.

Whitehorn, J. 2002. Female genital mutilation: cultural and psychological implications. Sexual Relationships and Therapy 17: 161-170.

WHO Study Group on Female Genital Mutilation and Obstetric Outcome. 2006. Female genital mutilation and obstetric outcome: WHO collaborative prospective study in six African countries. Lancet 367, 1835-1841

WHO. 2010. Global Strategy to Stop Health-Care Providers from Performing Female Genital Mutilation. Geneva: World Health Organisation.

WHO. 2016. Female Genital Mutilation Factsheet 241. www.who.int/mediacentre/factsheets/fs241/en

WHO. 2017. Classification of female genital mutilation. www.who.int/reproductivehealth/topics/fgm/overview/en 


\section{Appendix: List of Study Contributors}

\section{Government}

Federal level

Chris Ugboko (Federal Ministry of Health)

Grace Obiechina (Federal Ministry of Health)

Steven Nwankwo (Federal Ministry of Health)

Suleiman I. Nuhu (Federal Ministry of Health)

\section{State level}

Olukemi Akinleye (Ekiti state Ministry of Health)

Mabel Emerure (Delta state Ministry of Health)

Cecilia Marcus (Kaduna state Ministry of Health)

Maria Echehum (Imo state Ministry of Health)

\section{Data Collectors}

Ese Freeman Oghaghare (Delta state)

Iris Ajiroghene Imisa (Delta state)

Rita llevbare (Ekiti state)

Olayemi Ojo (Ekiti state)

Christabel Ifeoma Onyeneke (Imo state)

Desmond Denis (Imo state)

Salamatu Baba-Tunzwang (Kaduna state)

Alice Yakubu (Kaduna state)

\section{Study Participant Recruitment}

Benjamin Mbakwem (Community and Youth Development Initiatives - CYDI)

Ifeanyi Uzoetue (CYDI)

Abimbola Aladejare (New Generation Girls \& Women Development Initiative - NIGAWD)

Ehita Ikoghode Aikpitanyi (Girls' Power Initiative Asaba)

Elizabeth Anche 